\title{
Gains from Trade Liberalization with Flexible Extensive
}

\author{
Margin Adjustment* \\ Chang-Tai Hsieh \\ University of Chicago and NBER \\ Ralph Ossa \\ University of Zurich and CEPR \\ Nicholas Li \\ Ryerson University \\ Mu-Jeung Yang \\ University of Oklahoma
}

November 19, 2021

\begin{abstract}
We propose a new sufficient statistic to measure the ex-post welfare gains from trade in CES models featuring any productivity distribution or pattern of selection into production and exporting. Our statistic is based on a single data moment, the change in the market share of continuing domestic producers, and a single structural parameter, the elasticity of substitution between products. We apply our statistic to measure Canada's gains from the Canada-US Free Trade Agreement using data on observed firm selection and simulated firm selection in a calibrated model with a flexible extensive margin. We find that welfare gains are substantially smaller than implied by welfare formulas that assume that the extensive margin behaves according to a standard Melitz-Pareto model with iso-elastic import demand.
\end{abstract}

*Emails: chsieh@chicagobooth.edu; nicholas.li@ryerson.ca; ralph.ossa@econ.uzh.ch; mjyang@ou.edu. Financial support from IGM at Chicago Booth is gratefully acknowledged. The results of this paper have been screened by Statistics Canada and the US Census Bureau to ensure that no confidential data are revealed. 


\section{Introduction}

Seminal models by Krugman (1980) and Melitz (2003) show that changes in the set of firms serving domestic and foreign markets constitute an important "extensive" margin of adjustment in response to changes in trade costs. A large subsequent empirical literature has quantified partial aspects of these extensive margin entry/exit effects with micro data. For example, Broda and Weinstein (2006) quantify the welfare gains from increases in US import variety, while Pavcnik (2002) and Melitz and Trefler (2012) quantify increases in average domestic productivity associated with domestic exit by less productive firms and re-allocation of labor to more productive firms.

While firm-level micro data is necessary to quantify these individual effects, an influential paper by Arkolakis et al. (2012) (henceforth ACR) shows that for many trade models, detailed quantification of these entry, exit and re-allocation effects using micro-data is unnecessary to calculate welfare changes. Instead, welfare gains from changes in trade costs can be quantified using a sufficient statistic based only on the aggregate trade share and the aggregate trade elasticity. Their result assumes an iso-elastic import demand system. When trade is only affected at the intensive margin, this follows immediately from the standard Dixit-Stiglitz preferences. However, with extensive margin adjustment, iso-elastic import demand also requires that selection into exporting be such that the extensive margin trade elasticity is constant. The supply-side restrictions on firm heterogeneity that yield a constant extensive margin trade elasticity are restrictive, e.g. in the standard Melitz (2003) model any deviation from Pareto-distributed firm productivity or even simple deviations from strict selection into exporting lead to a variable extensive margin trade elasticity and hence an import demand system that is not iso-elastic.

In this paper, we argue that more flexible patterns of firm heterogeneity and selection could lead to significant biases when applying ACR and similar "welfare sufficient statistics" to data from trade liberalization. We propose a new formula to measure ex-post welfare gains in trade models with an extensive margin. Our proposed formula is based on one data moment, the domestic market share of continuing domestic producers, and one parameter, the elasticity of substitution between products. A key advantage of our formula is that it 
applies to a much wider range of trade models - for example, a generalized Melitz (2003) model with any productivity distribution and any pattern of selection into production and exporting. Another potential advantage is that by leveraging data on domestic selection, our statistic does not rely on estimation of a trade elasticity or the assumption that this elasticity is exactly or approximately constant.

Our analysis is partly motivated by the stylized fact that firm selection into export markets and exit does not follow strict sorting, as assumed in Melitz (2003). For example, Eaton et al. (2011) and Armenter and Koren (2015) show that there is a substantial overlap in the size distribution of exporters and non-exporters in France and the US. Figure 1 (top panel) replicates this evidence for U.S. and Canadian manufacturing. As can be seen, many exporters are smaller than non-exporters, and many non-exporters are larger than exporters. The bottom panel in Figure 1 shows that there is a similar overlap for exiting firms vs. continuing firms. Specifically, many exiting plants are ex-ante substantially larger than continuing firms in Canada and the US. These patterns of overlap are by now well known, but their implications for the welfare gains from trade in models of firm selection are not well understood. Most of the literature to date has focused on the quantitative importance of deviations from Pareto productivity for welfare gains from trade and this has produced amended welfare formulas that incorporate additional information on the (theoretical) productivity of firms at the margin of exporting or exiting. Our approach further relaxes this assumption of strict selection into markets based on firm productivity and the implied tight relationship between the firm productivity distribution and magnitude of extensive margin adjustment. While the firm selection response to a trade shock may be qualitatively captured by the standard Melitz model and the special iso-elastic Pareto case considered by ACR, we argue that measuring the quantitative effects requires a more flexible approach to capturing the net effect of changes on the extensive margin.

We therefore derive a more robust sufficient welfare statistic to quantify the ex-post gains from trade. Our approach is essentially an application of the well-known Feenstra (1994) formula, albeit one that is different from what is typically done in the literature. While prior papers such as Broda and Weinstein (2006) use the Feenstra (1994) method to measure the welfare gains from increasing import variety, we apply it to measure the overall welfare gains, 
gains that include domestic and foreign extensive margin adjustment as well as reductions in the price of continuing imports. For example, in a Melitz (2003) model, the welfare gains from a reduction in trade costs come from lower prices for existing imported products and access to new imported products net of the loss from domestic products that exit. The intuition behind our application of Feenstra (1994)'s formula is that new foreign products and lower prices of existing imported products take away the market of incumbent domestic firms, while the exit of domestic firms increases their market share. The change in the market share of domestic incumbent firms therefore captures the net effect of all three sources of welfare gains in the Melitz (2003) model. Domestic incumbent firms are a natural benchmark for calculating the value of domestic exit and changes in the price and variety of imports because the domestic real wage in terms of the output of these firms is fixed for a wide class of models and these firms produce a large share of all domestic consumption. ${ }^{1}$

We first apply our statistic to Canadian data from the Canada-US Free Trade Agreement liberalization period (1988-1996). Given the size of the trade shock from Canada's perspective combined with the relative absence of other major shocks, we view observed firm selection and welfare gains during this period as informative about the firm selection and welfare gains attributable to CUSFTA liberalization. We show that our welfare statistic implies substantially lower welfare gains than the ACR statistic during this period, primarily due to domestic exit effects that are larger than those that would be generated by a Melitz-Pareto model with an import elasticity chosen to match several distinct data moments.

We then simulate a CUSFTA-style trade shock using a two-country general equilibrium Melitz model that allows for deviations from both Pareto productivity and strict selection into exporting and production. In our model, firms face idiosyncratic export fixed costs as well as production fixed costs that are increasing in firm productivity. The model is calibrated using

\footnotetext{
${ }^{1}$ Models with no within-firm productivity changes or changes in domestic markups or other distortions have this implication. Empirically we recognize that there is growing evidence that trade affects within-firm innovation and productivity (see Melitz and Trefler (2012) for a review in the context of the CUSFTA or Kueng et al. (2020) for more evidence from Canadian manufacturing firms). We have little to add to the literature on estimation of firm-level productivity growth and markups, but note that to the extent that micro-data are available to estimate changes in firm productivity and markups, these are usually only available for continuing domestic incumbent firms, precisely the firms that our statistic uses as a benchmark. We return to the question of changes in the value of domestic incumbent firms later in our analysis and consider a variant of our sufficient statistic that allows us to capture some of these effects by specifying a subset of domestic firms that are less affected by CUSFTA liberalization as a benchmark.
} 
data from Canada and the United States to match the overlap in size between exporters and non-exporters and continuing and exiting firms in both countries seen in Figure 1) during the period before CUSFTA. Our flexible model leads to substantial deviations from the standard Melitz selection effects, as lower trade costs with the US can lead to exit by Canadian firms that are relatively large and productive in the domestic market (but face high export fixed costs) and entry by Canadian firms that are relatively unproductive and small in the domestic market (but can still make an overall profit thanks to the presence of a large US market and low exporting fixed costs). We use the model both to assess the extent to which observed firm selection and welfare gains during the 1988-1996 period can be causally attributed to a CUSFTA-style trade shock, and as a laboratory to study the bias in welfare statistics that impose iso-elastic demand or other restrictions on selection. We find that simulated data from the model can account for most of the observed selection and welfare gains during the CUSFTA period. We also find that several proposed welfare statistics, including Arkolakis et al. (2012)'s and local elasticity formulas used by Melitz and Redding (2015) and Head et al. (2014), can lead to substantial biases when applied to the data generated by our model. We conclude that deviations from iso-elastic import demand and strict sorting into markets are quantitatively relevant when measuring welfare gains from a major trade liberalization episode and that our robust sufficient statistic is therefore worth implementing when the data are available.

Our paper builds primarily on the Arkolakis et al. (2012) sufficient statistics approach to welfare gains from trade and the CES gains from variety approach developed by Feenstra (1994). Like Head et al. (2014) and Melitz and Redding (2015), we allow for departures from a Pareto distribution of firm productivity and therefore do not impose iso-elastic import demand. However, our welfare sufficient statistic and modeling exercise also allow for deviations from strict productivity-based sorting into production and export. These deviations from the standard Melitz model appear to be a common feature of trade data (Eaton et al. (2011), Armenter and Koren (2015)) as well as the CUSFTA setting, and they imply that productivity cutoffs and the firm size distribution are not enough to characterize the welfare implications of firm selection for the gains from trade. We differ from Eaton et al. (2011) and Armenter and Koren (2015) in that our focus is on how deviations from standard Melitz selection affect 
domestic exit and therefore welfare gains related to a trade shock.

Our paper is also related to two recent contributions by Fernandes et al. (2020) and Adao et al. (2020). Both papers use rich cross-country trade data to estimate models that allow for flexible extensive margin responses by relaxing the restrictive Pareto productivity and fixed cost assumptions that guarantee iso-elastic import demand. Fernandes et al. (2020) show how to estimate a flexible parametric log-normal model using firm-level export data. They find that the trade elasticity implied by their model varies only slightly (from 4 to 4.8 ), implying that the ACR formula can work well in practice even when the data-generating process is not Melitz-Pareto. Adao et al. (2020) show how to estimate non-parametric trade elasticity functions that flexibly capture the intensive and extensive margin firm response and summarize the welfare effects of trade shocks. They find some variation in the bilateral trade elasticity (4 to 7 ) and modest bias relative to an approach that assumes a constant trade elasticity (6-8\% on average).

The methods developed in Fernandes et al. (2020) and Adao et al. (2020) offer one significant advantage over our welfare formula in that they allow for counter-factual analysis, such as the gains from trade relative to autarky. However, the data and estimation requirements for both approaches are substantial, utilizing semi-parametric GMM or full structural estimation and requiring multi-country bilateral firm-level export data. Our ex-post sufficient statistic is remarkably simple and can be easily applied to a specific country liberalization episode without the need to estimate a trade elasticity, trade elasticity function, or the full structure of a model. Our sufficient statistic and model calibration also use micro-data on domestic sales and entry/exit patterns which highlights the important role of exit by large non-exporting Canadian firms due to CUSFTA. This contrasts with the analysis in Fernandes et al. (2020) and Adao et al. (2020) which focuses on bilateral trade flows and export market selection and in which data on domestic firm sales and net exit play a limited role. ${ }^{2}$

This paper also relates to our earlier work (Hsieh et al. (2020)) that explores the margins

\footnotetext{
${ }^{2}$ For example, Fernandes et al. (2020) do not use data on domestic sales or exit in their estimation. Both Fernandes et al. (2020) and Adao et al. (2020) at some point rely on an estimate of the number of entering firms (similar to the local elasticity formulas in Melitz and Redding (2015) and Head et al. (2014)) but since this is not observed, they need to assume that this is equal to the number of actual operating firms or make assumptions about how observed firm survival rates relate to the difference between entering and operating firms in a Melitz-style model.
} 
of domestic and foreign firm selection in the context of CUSFTA. Our focus here is on estimating the overall gains from trade liberalization rather decomposing the foreign and domestic extensive margins. In contrast to our earlier work, here we adopt a simulation-based approach to quantifying the contribution of CUSFTA liberalization to firm entry and exit.

The paper proceeds as follows. We first derive a new sufficient statistic for the gains from trade that holds for all trade models with CES preferences, including those where the import demand elasticity is not constant and firms do not sort into markets based on productivity only. We then use micro-data from Canadian manufacturing to calculate Canada's welfare gains from observed firm selection and cheaper foreign varieties for the 1988 to 1996 period after CUSFTA was signed. The last section uses a generalized two-country Melitz model calibrated to match Canadian and US data on firm size and selection to generate simulated data from a CUSFTA style shock and assess the extent of bias from welfare formulas that assume iso-elastic import demand or strict sorting into markets.

\section{A New Sufficient Statistic for the Gains from Trade Liber- alization}

This section derives our sufficient statistic for the gains from trade liberalization. In anticipation of our later application, we derive this statistic in the context of a generalized Melitz (2003) model where import demand is not necessarily iso-elastic. We do this by allowing the productivity distribution to take any form and by not imposing any restriction on selection into production and exporting. But it will become clear that our sufficient statistic also measures the gains from trade in a Ricardian model with an arbitrary distribution of productivity.

We start out with a representative consumer, who combines differentiated varieties in a CES utility. Varieties in turn are offered by firms, using production technology $y(\varphi)=\varphi \cdot l(\varphi)$, where $\varphi$ denotes firm-level productivity and $l(\varphi)$ denotes production labor used by firm of productivity level $\varphi$. Trade frictions between firms producing in country $i$ and shipping to country $j$ are denoted by $\tau_{i j}>1$. Importantly, we make no assumptions about the entry process and instead just denote by $M_{i j}$ the number of firms from country $i$ that offer goods in 
country $j$. As a result, there might be differential fixed costs for market access and selection into exporting might not obey strict sorting.

As a result of CES utility, demand from country $j$ consumers for products offered by firms from country $i$ with productivity $\varphi$ is given by $q_{i j}(\varphi)=\frac{p_{i j}(\varphi)^{-\sigma}}{P_{j}^{1-\sigma}} Y_{j}$, for which we denoted by $p_{i j}$ the delivered price in country $j$, while $P_{j}$ and $Y_{j}$ are price index and nominal income in country $j$ and $\sigma>1$ is the elasticity of substitution. As is usual we assume monopolistic competition, so that firms adopt optimal pricing with a constant markup: $p_{i j}(\varphi)=\frac{\sigma}{\sigma-1} \frac{w_{i} \tau_{i j}}{\varphi}$, with wages of the producer country given by $w_{i}$.

Bilateral trade flows can therefore be expressed as a function of average prices, $X_{i j}=$ $M_{i j}\left(\frac{\tilde{p}_{i j}}{P_{j}}\right)^{1-\sigma} Y_{j}$, where average prices are in turn a function of average productivities, $\tilde{p}_{i j}=$ $\frac{\sigma}{\sigma-1} \frac{w_{i} \tau_{i j}}{\tilde{\varphi}_{i j}}$, where $\tilde{\varphi}_{i j}$ is a weighted harmonic mean of productivity. ${ }^{3}$

Consider now a shock to the economy, which causes some firms to exit and others to enter. We focus on trade liberalization in our application but our method really applies to any shock. We denote by $M_{i j}^{c}$ the subset of continuing firms, defined as firms which are active both before and after the shock. Bilateral trade flows associated with continuing firms can be written as $X_{i j}^{c}=M_{i j}^{c}\left(\frac{\tilde{p}_{i j}^{c}}{P_{j}}\right)^{1-\sigma} Y_{j}$, where average prices and average productivity are defined only over this subset of firms, $\tilde{p}_{i j}^{c}=\frac{\sigma}{\sigma-1} \frac{w_{i} \tau_{i j}}{\tilde{\varphi}_{i j}^{c}}$. By definition, there are no changes in the set of continuing firms so that $M_{i j}^{c}$ remains unchanged and $\tilde{\varphi}_{i j}^{c}$ changes only if there are within-firm productivity effects (i.e. there are no Melitz-type selection effects on $\tilde{\varphi}_{i j}^{c}$ ).

We derive our sufficient statistic by focusing on the domestic market share of continuing domestic firms, $\lambda_{j j}^{c} \equiv \frac{X_{j j}^{c}}{Y_{j}}$. Using our expression for $X_{i j}^{c}$ above, we can express price index changes as $\Delta \ln P_{j}=\Delta \ln \tilde{p}_{j j}^{c}+\frac{1}{\sigma-1} \Delta \ln \lambda_{j j}^{c}$. From our expression for $\tilde{p}_{i j}^{c}$ above, we know that $\Delta \ln \tilde{p}_{j j}^{c}=\Delta \ln w_{j}-\Delta \ln \tilde{\varphi}_{j j}^{c}$ so that we can write changes in the domestic real wage as $\Delta \ln \frac{w_{j}}{P_{j}}-\Delta \ln \tilde{\varphi}_{j j}^{c}=-\frac{1}{\sigma-1} \Delta \ln \lambda_{j j}^{c}$. Changes in the domestic real wage are equal to changes in per-capita welfare if labor income is proportional to total income since then $\Delta \ln \frac{w_{j}}{P_{j}}=$ $\Delta \ln \frac{Y_{j} / L_{j}}{P_{j}} \equiv \Delta \ln W_{j}$. This holds, for example, under free entry and we impose this assumption

\footnotetext{
${ }^{3}$ Specifically, $\tilde{\varphi}_{i j} \equiv\left(\int_{\varphi \in \Phi_{i j}} \varphi^{\sigma-1} d G_{i}\left(\varphi \mid \varphi \in \Phi_{i j}\right)\right)^{\frac{1}{\sigma-1}}$, where $\Phi_{i j}$ is the set of productivities corresponding to all country $i$ firms serving country $j$ and $G_{i}\left(\varphi \mid \varphi \in \Phi_{i j}\right)$ is their cumulative distribution.
} 
henceforth. We can thus write:

$$
\Delta \ln W_{j}-\Delta \ln \tilde{\varphi}_{j j}^{c}=-\frac{1}{\sigma-1} \Delta \ln \lambda_{j j}^{c}
$$

This equation says that anything that affects welfare, other than the productivity of continuing domestic firms, shows up as changes in $\lambda_{j j}^{c}$. One implication of this is that the effect of changes in trade costs on welfare, including the effect of any reallocation and entry and exit induced by the change in trade costs, can be measured by one simple statistic, the change in the domestic market share of continuing domestic firms $\Delta \ln \lambda_{j j}^{c}$, and one parameter, the elasticity of substitution $\sigma$.

We want to make clear two points about our proposed statistic for the gains from trade in equation (1). First, while it captures all welfare effects from domestic net entry and changes in the price or variety of foreign imports when comparing two equilibria, interpreting it as the welfare gains from trade assumes that all of these changes are brought about by trade. This may not be true. For example, in a closed economy our sufficient statistic boils down to $\frac{1}{\sigma-1} \Delta \ln \lambda^{c}=\frac{1}{\sigma-1} \Delta \ln M_{j j}+\Delta \ln \frac{\tilde{\varphi}_{j j}}{\tilde{\varphi}_{j j}^{c}}$, which is simply the gains from entry of new domestic varieties net of the losses from domestic exit.

Second, even if the changes underlying computation of 1 are driven by trade, we do not know whether they are due to changes in trade costs, e.g. import tariff cuts negotiated under CUSFTA. For example, differential productivity growth (domestic vs. foreign) or changes in the fixed cost of exporting can also affect welfare through domestic net entry and changes in the price and variety of foreign imports. Thus while we apply our formula to data on observed trade flows and domestic firm selection during the CUSFTA period in section 4, we acknowledge that these data potentially reflect factors other than reductions in bilateral Canada-US trade costs. Our approach to assessing the specific contribution of the reduction in trade costs under CUSFTA to welfare gains is to specify and calibrate a general equilibrium model, which we do in section 5 .

We end this section by comparing our sufficient statistic in equation (1) with two influential statistics by Feenstra (1994) and ACR. First, our formula can be thought of as an application of Feenstra (1994), albeit one that is very different from what is typically done in the literature. 
While prior papers such as Broda and Weinstein (2006) use Feenstra (1994) to measure the import variety gains from trade, we apply it to measure the overall gains from trade. Feenstra (1994) decomposes price index changes $(\Delta \ln P)$ into a term capturing changes in the prices of continuing goods $\left(\sum_{i \in I^{c}} \bar{\mu}_{i}^{c} \Delta \ln p_{i}\right.$, where $I^{c}$ is a subset of continuing goods and $\bar{\mu}_{i}^{c}$ are Sato-Vartia weights) and a residual commonly thought of as capturing changes in the set of available goods (the "Feenstra ratio" $\frac{1}{\sigma-1} \Delta \ln \lambda^{c}$ ). However, the set $I^{c}$ can be defined to include any subset of goods available in both periods in which case the Feenstra ratio term also captures the welfare effects of changes in the prices of any goods excluded from the chosen set of continuing goods $I^{c}$. Our approach essentially boils down to choosing the subset of continuing goods that are produced in the home country. Intuitively, the market share of continuing domestic goods measures the net effect of all the margins of adjustment triggered by a change in trade costs. In a model with only adjustment on the intensive margin, the share of continuing domestic goods falls when a reduction in trade costs lowers the prices of foreign goods. In models that also have adjustment on the extensive margin, the share of continuing domestic goods also falls with more and better entering foreign varieties and rises with more and better exiting domestic varieties.

Note that in principle this also allows a researcher to choose a set of continuing goods for which productivity changes can be directly measured or are expected to be zero, eliminating the unknown "continuing firm productivity term" in equation (1). Any changes in the productivity of excluded firms, foreign or domestic, is then captured by the Feenstra ratio. We provide an illustrative example in the appendix (section A2) where we restrict the set of continuing domestic firms in $I^{c}$ to only those in sectors that had initially low tariffs and hence experienced minimal tariff decreases due to CUSFTA.

Second, our sufficient statistic in equation (1) is also a generalization of the formula by ACR. While we derived this sufficient statistic in a generalized Melitz (2003) model, it should be clear from our derivations that it holds in all models satisfying $X_{i j} \propto M_{i j}\left(\frac{\tilde{p}_{i j}}{P_{j}}\right)^{1-\sigma} Y_{j}$, $\tilde{p}_{i j} \propto \frac{w_{i} \tau_{i j}}{\tilde{\varphi}_{i j}}$, and $w_{j} L_{j} \propto Y_{j}$. For example, it also holds in a generalized Eaton and Kortum (2002) model that allows for an arbitrary productivity distribution if $M_{i j}$ is reinterpreted

\footnotetext{
${ }^{4}$ In principle this approach could also be used to capture markup variation or changes in within-firm product variety when these can be directly measured or ignored for a subset of firms.
} 
as the number of goods shipped from country $i$ to country $j$. Recall that ACR require four "model primitives" - (i) Dixit-Stiglitz preferences, (ii) one factor of production, (iii) linear cost functions, and (iv) perfect or monopolistic competition - and three "macro-level restrictions" - (i) trade is balanced, (ii) aggregate profits are a constant share of aggregate revenues, and (iii) the import demand system is iso-elastic (with constant trade elasticity $\epsilon$ ). Their model primitive (i) immediately implies our first key equation $X_{i j} \propto M_{i j}\left(\frac{\tilde{p}_{i j}}{P_{j}}\right)^{1-\sigma} Y_{j}$, while their model primitives (i)-(iv) together yield our second key equation $\tilde{p}_{i j} \propto \frac{w_{i} \tau_{i j}}{\tilde{\varphi}_{i j}}$. Our third key equation $w_{j} L_{j} \propto Y_{j}$ follows from their macro-level restrictions (i) and (ii) so that we effectively relax their macro-level restriction (iii).

To see how the iso-elastic import demand restriction relates to the differences between our formula and ACR's, observe that our formula (holding within-firm productivity constant) can be written as $\Delta \ln W=-\frac{1}{\sigma-1} \Delta \ln \lambda_{j j}-\frac{1}{\sigma-1} \Delta \ln \frac{X_{j j}^{c}}{X_{j j}}$ while the ACR formula is given by $\Delta \ln W=-\frac{1}{\epsilon} \Delta \ln \lambda_{j j}$. With no extensive margin adjustment the domestic net exit term $\Delta \ln \frac{X_{j j}^{c}}{X_{j j}}$ in our formula drops out, the trade elasticity $(\epsilon)$ in ACR's formula equals $\sigma-1$, and both formulas deliver equal welfare gains. With extensive margin adjustment, ACR's formula allows quantification of welfare changes between any equilibrium trade shares including hypotheticals like autarky $\left(\lambda_{j j}=1\right)$. Our formula requires that we observe the change in the domestic share of continuing domestic firms $\left(\Delta \ln \frac{X_{j j}^{c}}{X_{j j}}\right.$, or equivalently $\left.\Delta \ln \lambda_{j j}^{c}\right)$, which is clearly not observed for hypthotheticals (except under the extreme assumption that the set of domestic firms is unchanged). However, under the assumption that import demand is iso-elastic, the two formulas must deliver equal welfare gains. This implies the following relationship between the quantities and elasticities in the two formulas: $\epsilon /(\sigma-1)=\frac{1}{1+\frac{\Delta \ln \left(X_{j j}^{c} / X_{j j}\right)}{\Delta \ln \lambda_{j j}}}$. This equality highlights that relative to our more flexible formula, imposing the additional ACR restriction of iso-elastic import demand imposes (a) strict proportionality of changes in the trade share and domestic share of continuing domestic firms and (b) changes in these shares that have a relative magnitude pinned down by the ratio of the trade to intensive margin elasticity $\epsilon /(\sigma-1) .{ }^{5}$ Our formula relaxes the ACR iso-elastic import demand restriction by

\footnotetext{
${ }^{5}$ Note that under Melitz-Pareto, the trade elasticity $\epsilon$ is equal to the Pareto shape parameter $(\theta)$. Di Giovanni and Levchenko (2013) observe that Zipf's law implies that $\theta /(\sigma-1)$ is close to one, and that consequently the extensive margin contributes little to welfare or the trade elasticity under this assumption. This can be seen in the expression above as $\epsilon /(\sigma-1)$ close to one implies that $\Delta \ln \frac{X_{j j}^{c}}{X_{j j}}$ is close to zero for any $\Delta \ln \lambda_{j j}$.
} 
leveraging data on domestic exit rather than assuming that domestic exit can be derived from an estimate of the trade elasticity and change in the trade share. In the appendix (section A1), we elaborate further on the link between our formula and ACR's and the local elasticity formula in Melitz and Redding (2015)).

In an earlier paper (Hsieh et al. (2020)), we showed how the Melitz framework analyzed here generalizes to richer economic environments. In particular, we considered non-traded and intermediate goods, endogenous markups, tariff revenue ${ }^{6}$, multiproduct firms, and heterogeneous quality. The bottom line is that only minor (if any) adjustments are needed to accommodate these extensions and they mostly reflect data issues (e.g. do the data capture continuing domestic products versus establishments versus firms, do quality changes result in new/replacement products) so we do not elaborate on them here. Our empirical application focuses on entry and exit of manufacturing establishments as these are the most comprehensive data available to study selection in the context of CUSFTA and because our model will also focus on this central mechanism of the Melitz model.

\section{Data}

The Canada-US Free Trade Agreement (CUSFTA) was signed on January 2, 1988 and mandated the elimination of bilateral import tariffs in manufacturing, phased-in over a ten-year period starting on January 1, 1989. By 1996, Canadian tariffs on US imports had fallen from an average of $8 \%$ (equivalent to a $16 \%$ effective tariff rate) to about $1 \%$. US tariffs on Canadian imports fell from about 4\% in 1988 to below 1\% during this period. Bilateral manufacturing trade almost doubled during this period and the agreement represents a large shock for Canada's manufacturing sector as about $70 \%$ of its trade is conducted with the US. Given the size of the shock and the relative absence of major macroeconomic reforms or crises during this period (discussed in Trefler (2004)) we view observed selection during the CUSFTA period as potentially informative about the size and nature of selection effects induced by trade liberalization and the consequent welfare gains.

To implement our formula we need information on domestic sales of continuing firms in

\footnotetext{
${ }^{6}$ For reference we note that Canadian tariff revenue fell as a share of spending from $0.69 \%$ to $0.18 \%$ between 1988 and 1996.
} 
Canada before and after CUSFTA came into force. We use the micro-data from Canada's Annual Survey of Manufacturing Establishments, so what we call "firms" going forward are really manufacturing plants and we are less concerned with how mergers might affect our estimates of exit. ${ }^{7}$ This survey covers all but the very smallest Canadian manufacturing establishments with sales below $\$ 30,000$ Canadian dollars. Our analysis focuses on the 19781988 and 1988-1996 time periods. We consider the 1978-1988 period as the "pre-CUSFTA" and the 1988-1996 period as "post-CUSFTA" period. ${ }^{8}$ The information we use from these data include establishment id, exports, and sales. In each of the two time periods, we use the establishment id to identify firms as entrants, exiters, and continuing firms. We define an entrant as an establishment not in the data at the beginning of the time period, an exiter as an establishment not in the data at the end of the time period, and a continuing establishment as one that was present in the data at the beginning and at the end of a time period.

We supplement these data on domestic sales by Canadian manufacturing establishments with data on Canadian manufacturing imports. Our main results assume that Canadian manufacturing exports (which we can measure directly in the same Canadian establishment data mentioned above) are equal to Canadian manufacturing imports. This reflects the assumption we also make in section 5 that (manufacturing) trade is balanced and the US is the only trading partner. However, we can also use import data from Statistics Canada that directly captures Canada's imports of manufactured goods from the US or the World, and we report alternative estimates using these data in Appendix Table 8. These data suggest that while neither balanced trade nor exclusive trade with the US hold exactly in the data, they are not too far off and using them will not alter our main conclusions.

The last thing we need to apply our formula is the elasticity of substitution, and we use the estimates from Oberfield and Raval (2014) based on firm markups in US manufacturing. ${ }^{9}$ The elasticities at the two-digit level range from 3.3 to 4.4 and average to 3.7. Since we only use aggregate data, we simply work with the average elasticity of $3.7 .{ }^{10}$

\footnotetext{
${ }^{7}$ This survey was initially called the Census of Manufactures and is now known as Annual Survey of Manufactures.

${ }^{8} \mathrm{We}$ also chose these time periods because Statistics Canada officials indicated to us that the years with the best sampling frame are 1978, 1988, and 1996.

${ }^{9}$ See Table VII of Oberfield and Raval (2014)'s online appendix. We used the concordance from Peter Schott's website to match them to 2-digit Canadian SIC codes.

${ }^{10}$ This value is also consistent with mean elasticities estimated using panel import data for the US (Broda
} 
Note that equation (1) says that all we need to measure the gains from trade is the change in the Canadian market share of continuing Canadian firms, which we can calculate using only the Canadian firm data and aggregate import data. When we later calibrate a model to the pre-CUSFTA equilibrium in section 5, we also use micro-data on Canadian firm size and exports to the US, US firm size and exports to Canada, and US firm exit. We supplement the Canadian micro-data with micro-data from the quinquennial US manufacturing census, which provides data on employment and exports at the establishment level starting in $1987 .{ }^{11}$

\section{Canada's welfare gains during CUSFTA period}

In this section, we present our data on sales of entering and exiting firms and trade flows during the CUSFTA period (1988-1996) and apply our sufficient statistic (1) to measure welfare gains in Canada. As discussed earlier, this simple before-after analysis may not identify the causal effect of the trade policy changes mandated by CUSFTA given other domestic and foreign shocks during this period, but given the size of the CUSFTA shock we view it as informative. We also present data on the pre-CUSFTA period (1978-1988) for comparison, as these may be informative about trends or firm dynamics in Canada during a period without major trade shocks. ${ }^{12}$ In the next section we use a quantitative model to isolate a trade shock similar to CUSFTA, and our conclusion will be that as much as $90 \%$ of the welfare gains implied by our simple before-after analysis here can be causally attributed to reductions in trade costs due to CUSFTA.

We begin by presenting detailed data on firm entry and exit in Table 1 with three columns for the 1978-1988 CUSFTA pre-period (column 1), the 1988-1996 CUSFTA post-period (column 2), and US exporters (column 3). Exiting firms are defined as those that exit between $t$ and $t+1$, while entering firms are defined as those that enter between $t$ and $t+1$. The first two rows in Table 1 show the number of exiting and entering plants as a share of all and Weinstein (2006)) and Canada (Chen and Jacks (2012)) at similar levels of aggregation, and the median value of 3.9 estimated by Hottman et al. (2016) using panel scanner data.

${ }^{11}$ The US census does not report establishment level exports by destination country so we assume that all US exporters in manufacturing also export to Canada. Canadian customs collects transaction-level data on imports from the US, but this data is only available after 1992 and cannot be reliably matched to US firms. US customs does not separately collect transaction-level data on exports to Canada.

${ }^{12}$ As the pre-period is 10 years and the CUSFTA period is 8 years, we multiply pre-period changes by $8 / 10$ to make them more comparable. 
plants, and the third row shows the implied change (over an 8-year period) in the number of plants. The key facts here are that over the 1988-1996 period, the number of Canadian plants decreased, which pushes up the domestic revenue share of continuing Canadian plants relative to all Canadian plants, and the number of US exporters increased, which we will see contributed to a lower share of the domestic market captured by Canadian plants.

Entry and exit also potentially change average productivity through selection effects. These effects are shown in the middle rows of Table 1 . The fourth and fifth rows show the raw data, namely sales of exiting firms relative to all firms (at the beginning of the period) and sales of entering firms relative to all firms (at the end of the period). As expected, exiting and entering firms are smaller than the average firm. The net effect of entry and exit on average productivity is then given by $\Delta \ln \left(\tilde{\varphi}_{i j} / \tilde{\varphi}_{i j}^{c}\right)=\frac{1}{\sigma-1} \Delta \ln \left(\tilde{r}_{i j}^{c} / \tilde{r}_{i j}\right)$ where $\tilde{r}$ denotes average revenues. This number is shown in the sixth row of Table 1. Net entry of new US exporters lowered the average productivity of US exporters. Net exit by Canadian firms during this period only had small effects on average productivity as the entering firms were smaller relative to continuing firms than the exiting firms. However, domestic firm selection during the CUSFTA period clearly increased average productivity of Canadian firms relative to the period before CUSFTA (in 1978-1988) when exiting firms and entering firms were smaller relative to continuing firms.

The last two rows of Table 1 combine information on the number and relative sales of exiting and entering domestic firms to show the total domestic sales of exiting and entering Canadian firms as a share of domestic sales of all Canadian firms. A key fact is that the share of exiting firms increased, from $24.41 \%$ to $28.01 \%$ between 1978-1988 and 1988-1996, while the same share for entrants declined from $21.55 \%$ to $18.81 \%$. Combined, these lead to a much larger decline in the share of the domestic market captured by continuing domestic firms relative to all domestic firms during the post-CUSFTA period than the pre-CUSFTA period.

We re-emphasize the point that what matters for welfare is the net effect of the extensive and the intensive margins, and that our sufficient statistic for this net effect does not require such detailed data. Once we have data on domestic market shares of exiting and entering domestic firms (the last two rows of Table 1), we do not need to know the contribution of 
Table 1: Variety, Productivity, and Revenue from Entry and Exit

\begin{tabular}{|c|c|c|c|}
\hline & \multicolumn{2}{|c|}{ Canadian Firms } & \multirow{2}{*}{$\begin{array}{c}\text { US Exporters } \\
1987-1997\end{array}$} \\
\hline & $1978-1988$ & $1988-1996$ & \\
\hline \multicolumn{4}{|l|}{ Variety Margin } \\
\hline Exiters ( $\%$ of All Plants) ${ }^{1}$ & $51.68 \%$ & $49.56 \%$ & $54.69 \%$ \\
\hline Entrants ( $\%$ of All Plants) ${ }^{2}$ & $64.46 \%$ & $43.76 \%$ & $72.87 \%$ \\
\hline$\Delta \ln M_{i j}{ }^{3}$ & $24.57 \%$ & $-10.90 \%$ & $41.04 \%$ \\
\hline \multicolumn{4}{|l|}{ Productivity Margin } \\
\hline Exiters (Size relative to all plants) ${ }^{4}$ & $47.23 \%$ & $56.52 \%$ & $64.86 \%$ \\
\hline Entrants (Size relative to all plants) ${ }^{5}$ & $33.44 \%$ & $42.99 \%$ & $53.14 \%$ \\
\hline$\Delta \ln \tilde{\varphi}_{i j} / \tilde{\varphi}_{i j}^{c}{ }^{6}$ & $-10.20 \%$ & $-0.42 \%$ & $-13.67 \%$ \\
\hline \multicolumn{4}{|l|}{ Revenues } \\
\hline Exiter Domestic Revenue Share ${ }^{7}$ & $24.41 \%$ & $28.01 \%$ & \\
\hline Entrant Domestic Revenue Share ${ }^{8}$ & $21.55 \%$ & $18.81 \%$ & \\
\hline
\end{tabular}

1 \# exiting plants/total \# of plants (columns 1-2) or exiting exporters/total \# of exporters (column 3) at beginning of each period.

${ }^{2}$ \# new plants/total \# of plants (columns 1-2) or new exporters/total \# of exporters (column 3) at end of each period.

$3 \%$ change in total \# of plants (columns 1-2) or exporters (column 3).

${ }^{4}$ Average domestic revenues of exiting plants/all plants (columns 1-2) or average exports of exiting exporters/all exporters (column 3) at beginning of period.

5 Average domestic revenues of new plants/all plants (columns 1-2) or average exports of new exporters/all exporters (column 3) at end of period.

6 Productivity growth of all plants/continuing plants (columns 1-2) or all exporters/continuing exporters (column 3), measured as $\Delta \ln \tilde{\varphi}_{i j} / \tilde{\varphi}_{i j}^{c}=-\frac{1}{\sigma-1} \Delta \ln \frac{\tilde{r}_{i j}^{c}}{\tilde{r}_{i j}}$ where $\tilde{r}$ denotes average revenues.

7 Total domestic revenues of exiting Canadian firms/total domestic revenues of all Canadian firms at beginning of each period.

${ }^{8}$ Total domestic revenues of entrant Canadian firms/total domestic revenues of all Canadian firms.

Notes: Columns 1 and 3 impute 8-year change from 10-year changes. Calculated from micro-data of Canada's Annual Survey of Manufacturing and US Manufacturing Census. See text for details.

the number of plants or plant revenue to these shares. Put differently, exit is always welfare reducing and entry is always welfare enhancing, and how much they matter is measured by the revenue shares of these firms relative to the continuing domestic firms. Because our statistic uses domestic continuing firms as the benchmark, we do not need US micro data. US micro data is helpful for calibrating our quantitative model later, but to measure the welfare effects of observed firm selection using our formula we only need data on total imports.

Table 2 presents the key data moments that inform our welfare statistic and their magnitudes during the pre- and post-CUSFTA periods. Row 1 in Table 2 shows the change in the 
share of continuing domestic firms as a share of all domestic firms implied by the change in the share of entrants and exiters in the last two rows of Table 1. The change in the sales of continuing domestic firms as a share of sales of all domestic firms increased from $2.97 \%$ before CUSFTA (1978-1988) to $12.03 \%$ after CUSFTA (1988-1996). Equation (1) says that the key statistic is the change in domestic sales of continuing domestic firms as a share of total sales in the domestic market. This is simply the sum of the change in sales of continuing domestic firms as a share of all domestic firms shown in row 1 and the share of domestic firms in total sales. The latter, shown in Row 2, indicates that the market share of domestic Canadian firms fell massively - almost $24 \%$ - in the eight years after CUSFTA went into effect. This decrease is particularly notable relative to the very small $(1.36 \%)$ decrease in the market share of domestic Canadian firms in the period prior to CUSFTA. The last row shows $\Delta \ln \lambda_{j j}^{c}$ as the sum of rows 1 and 2. The share of continuing domestic firms in total sales in the Canadian market fell by $11.83 \%$ in $1988-1996$, compared to an increase of $1.61 \%$ in the period prior to CUSFTA.

Table 2: Revenue Shares of Canadian firms in Canadian Market

\begin{tabular}{lccc}
\hline & $1978-1988$ & $1988-1996$ & Difference \\
\cline { 2 - 4 }$\Delta \ln X_{j j}^{c} / X_{j j}{ }^{1}$ & $2.97 \%$ & $12.03 \%$ & $9.06 \%$ \\
$\Delta \ln \lambda_{j j}{ }^{2}$ & $-1.36 \%$ & $-23.86 \%$ & $-22.50 \%$ \\
$\Delta \ln \lambda_{j j}^{c}{ }^{3}$ & $1.61 \%$ & $-11.83 \%$ & $-13.44 \%$ \\
\hline
\end{tabular}

${ }^{1}$ Change in domestic revenues of continuing Canadian firms/all Canadian firms.

2 Change in total domestic sales of all Canadian firms/total sales in Canadian market assuming Canadian manufacturing imports=Canadian manufacturing exports in firm data.

${ }^{3}$ Change in total domestic revenues of continuing Canadian firms/total sales in Canadian market.

Sources: Column 1 (1978-1988) imputes the share or changes over 8 years based on the change over 10 years. Calculated from micro-data of Canada's Annual Survey of Manufacturing. See text for details.

Table 3 shows the welfare gains calculated as $-\frac{1}{\sigma-1} \Delta \ln \lambda_{j j}^{c}$, where we assume that $\sigma=3.7$ and subtract the pre-trend (we use the "Difference" column in Table 2) to calculate $\ln \lambda_{j j}^{c}$. The first row in the table says that Canadian welfare rose by almost 5\% over the 1988-1996 CUSFTA period from the net effect of domestic exit, US entry and lower prices for continuing US firms. Appendix section A3 Table 8 presents additional results that consider alternative 
measures of manufacturing imports and that do not subtract the pre-CUSFTA period trend - these indicate a similar magnitude of welfare gains (ranging from $4.5 \%$ to $7 \%$ ). Note that these estimates will underestimate the total welfare gains during this period if productivity for continuing Canadian firms grew, regardless of whether this within-firm productivity growth can be attributed to CUSFTA or other factors. Appendix section A2 provides additional analysis of the potential magnitude of these effects using a similar framework under the assumption that only continuing firms in industries with high initial tariffs were affected by CUSFTA, yielding welfare gains as high as $10 \%$.

The next two rows of Table 3 report welfare gains assuming iso-elastic import demand. In particular, we can use ACR's sufficient statistic if we assume that firm productivity follows a Pareto distribution and there is strict productivity-based sorting into production and exporting. With these two assumptions, the welfare gains (assuming no within-firm productivity changes) are given by:

$$
\Delta \ln W_{j}=-\frac{1}{\theta} \Delta \ln \lambda_{j j}
$$

where $\theta$ represents both the trade elasticity $(\epsilon)$ and the shape parameter of the Pareto distribution for this model. There are two differences between (2) and (1). First, $\lambda_{j j}$ in equation (2) is the share of all domestic firms while $\lambda_{j j}^{c}$ in equation (1) is the share of continuing domestic firms. The former is the number in row 2 in Table 2 and the latter is the number in row 3. Second, the elasticity in equation (2) is a trade elasticity, while the elasticity in equation (1) is a function of the elasticity of substitution across varieties.

So the only additional number we need to estimate equation (2) is $\theta$. We can estimate this parameter in at least three ways. The first two involve moments derived from observed changes during the CUSFTA period. First, we can use the fact that with an (untruncated) Pareto distribution, $\theta=-\Delta \ln \left(\frac{M_{i j} / M_{j j}}{\tilde{\varphi}_{i j} / \tilde{\varphi}_{j j}}\right)$ (see Hsieh et al. (2020) for the derivation). A second approach is to estimate a trade elasticity using changes in observed trade shares and an estimate of the change in trade costs. In particular, Melitz and Redding (2015) propose the "arc elasticity" $\theta=-\frac{\Delta \ln \frac{\left(1-\lambda_{j j}\right)}{\lambda_{j j}}}{\Delta\left(1+\tau_{i j}\right)}$. A third way is to use the distribution of firm size in the steady state. Specifically, if the distribution of firm productivity follows a Pareto distribution, $\theta$ is the product of $\sigma-1$ and the elasticity of the rank of firm size with respect to firm size 
(which is approximately unity according to Zipf's law).

We use our micro-data from Canada and the US to estimate $\theta$ using these three methods. For the first method, we use the $\Delta \ln M$ and $\Delta \ln \tilde{\varphi}$ from 1978-1988 to 1988-1996 (shown in Table 1), which gives us $\theta=2.9$. This estimate for $\theta$ is almost identical to that obtained from the cross-sectional distribution of firm size. Specifically, the elasticity of firm rank with respect to firm size is 1.06 , which combined with $\sigma=3.7$ yields $\theta=2.86$. Finally, we estimate $\theta$ from the "arc-elasticity" proposed by Melitz and Redding (2015) as $\theta=\frac{\Delta \ln \frac{\left(1-\lambda_{j j}\right)}{\lambda_{j j}}}{\left(\Delta 1+\tau_{i j}\right)}$. As we will describe later, we estimate that CUSFTA lowered the iceberg trade cost of shipping goods from the US to Canada by $23 \%$, which combined with the change in $\lambda_{j j}$ (shown in Table 2) yields $\theta=2.63$.

The last two rows in Table 3 calculate the ACR statistic using these two values of $\theta$. Using $\theta=2.9$, ACR's statistic suggests that CUSFTA increased welfare by $7.76 \%$. Using $\theta=2.63$, the ACR formula's gains are even larger, at 8.56\%. These numbers are 50\%-70\% larger than our estimate of $4.98 \%$, shown in the first row of the table. The welfare gains implied by the ACR formula remain substantially higher than the estimates using our formula regardless of whether we use different sources of import data or whether we take differences with respect to the pre-CUSFTA period (Appendix Table 8). One way to interpret this bias is to note that given the observed change in the trade share $\lambda_{j j}$, ACR's formula predicts only small accompanying changes in the domestic market share of continuing domestic firms relative to all domestic firms for the given the parameters $\theta$ and $\sigma$. In the data, this share falls a lot, meaning that the combined number and relative size of exiting domestic firms exerted a substantial negative effect on welfare during this period. ${ }^{13}$

\footnotetext{
${ }^{13}$ Note that in principle the ACR formula could deliver exactly the same welfare and domestic exit term as our formula with a high enough trade elasticity (around 5), but for Melitz-Pareto this also implies an elasticity of firm size with respect to firm rank of around $2(\theta /(\sigma-1)=5 / 2.7)$ which is far above any existing estimates. Combining a higher trade elasticity with a higher value of $\sigma$ would improve consistency with Zipf's law but then our formula delivers even lower welfare gains implying the ACR statistic is still biased upward given that the change in the domestic exit term is large relative to the trade share term in the data. Our data-derived estimates of the trade elasticity are on the low side for the gravity literature but is only a bit below the aggregate elasticity estimates in Table 1 column 3 from Caliendo and Parro (2015). Adao et al. (2020) also observe that lower trade elasticities result when a high share of firms export and over $36 \%$ of our Canadian firms export to the US in 1988.
} 
Table 3: Alternative Estimates of Canada's Welfare Gains after CUSFTA

\begin{tabular}{lc}
\hline & $\Delta$ Welfare \\
Our statistic: $-\frac{1}{\sigma-1} \Delta \ln \lambda_{j j}^{c}$ & $4.98 \%$ \\
ACR with $\theta=2.9^{1}$ & $7.76 \%$ \\
ACR with $\theta=2.63^{2}$ & $8.56 \%$ \\
\hline
\end{tabular}

1 ACR welfare statistic (2) using $\theta=-\Delta \ln \left(\frac{M_{i j} / M_{j j}}{\tilde{\varphi}_{i j} / \tilde{\varphi}_{j j}}\right)$ or using Zipf's Law calculated as $\theta=\xi \cdot(\sigma-1)$ where $\xi$ is the elasticity of firm rank with respect to firm employment.

2 ACR welfare statistic (2) with arc-elasticity proposed by Melitz and Redding (2015) and measured as $\theta=\Delta \ln \frac{\left(1-\lambda_{j j}\right) / \lambda_{j j}}{\left(1+\tau_{i j}\right)}$

Note: Table shows the welfare gains for Canada based on the "Difference" column data moments in Table 2.

\section{CUSFTA model simulation}

In this section, we use a quantitative trade model to assess whether the observed change in the continuing domestic firm market share used by our welfare sufficient statistic in Table 3 is consistent with a CUSFTA-sized trade shock - that is, we ask whether the welfare gains implied by the trade flows and firm entry/exit we observe can be interpreted as being mainly welfare gains from trade. Because our quantitative model makes the same assumptions required to implement our welfare statistic, it is not useful for evaluating bias in our statistic (i.e. the model implied welfare gains are the same as what you would get applying our formula to model simulated data). However, it is useful for evaluating the size and direction of the bias from other proposed welfare statistics derived from more restrictive assumptions such as iso-elastic import demand or strict sorting into markets based on productivity. To that end, we consider two models that begin from the Melitz-Pareto benchmark but relax some of its central assumptions to better fit moments of the data related to firm size and sorting into markets.

Our first model follows Melitz and Redding (2015). Specifically, we assume two countries populated by representative consumers with CES preferences, firms pay a common fixed cost to produce in each period and another fixed cost to export, and the steady-state distribution of firm productivity follows a truncated Pareto distribution. ${ }^{14}$ In this model, the truncation

\footnotetext{
${ }^{14}$ We also assume free entry (after paying the fixed cost of entry) and balanced trade.
} 
parameter (combined with the observed share of firms that export) determines the extent of the departure from an iso-elastic import demand. We let the data dictate the truncation parameter to match the average size of exporters to non-exporters (similar to Melitz and Redding (2015)). With a large enough truncation parameter, the model will be quantitatively close to a Melitz-Pareto model with iso-elastic import demand.

Our second model also drops the assumption that all firms face the same fixed cost of production and exporting. We do this for two reasons. First, there is abundant evidence that strict sorting into exporting may not hold empirically. Eaton et al. (2011) and Armenter and Koren (2015) show that there is a substantial overlap in the size distribution between exporters and non-exporters in France and the US. Figure 1 (top panel) plots the distribution of employment for exporting and non-exporting establishments in our Canadian and US data, and shows that a similar fact holds in Canada and the US. We can capture the fact that many exporters are smaller than non-exporters, and vice versa, by allowing the fixed cost of exporting to differ across firms. Specifically, we assume that export fixed costs in each country are i.i.d. Pareto as in Armenter and Koren (2015), with a shape parameter $(\alpha)$.

Second, the likelihood that a plant exits in response to a shock may be only weakly tied to its initial size, measured by revenues or employment. The bottom panel in Figure 1 plots the ex-ante distribution of plant size for exiting vs. continuing firms in US and Canadian manufacturing. As can be seen, many exiting plants are ex-ante substantially larger than continuing plants, and vice versa. We will also allow our model to reproduce this pattern, this time by relaxing the assumption that the fixed cost of domestic production is the same across firms. Specifically, we allow production fixed costs to vary with firm productivity according to $f_{d}+\beta \ln \varphi .^{15}$ Note that we do not impose $\beta \neq 0$ but calibrate it using the data on exit during the pre-CUSFTA period and the assumption that during normal times firms are subject to idiosyncratic, proportional productivity shocks. The appendix (section A4) provides more detail on our models and our solution algorithm. We note here that relative to other model calibration exercises that allow for flexible extensive margin responses (e.g.

\footnotetext{
${ }^{15}$ The intuition for this assumption is that high productivity production processes may require higher setup fixed costs (see Sutton (1991) and Kugler and Verhoogen (2012)), but there are other specifications of heterogeneous fixed domestic production costs that could help to rationalize the extent of overlap in the size of continuing and exiting plants.
} 
Figure 1: Distribution of Employment

US

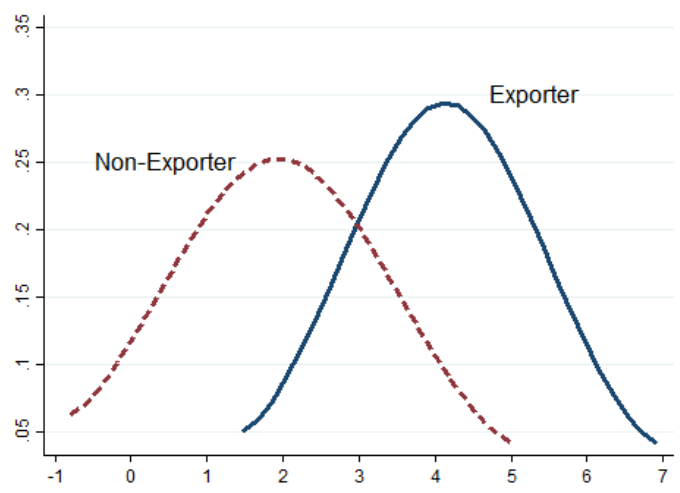

CANADA

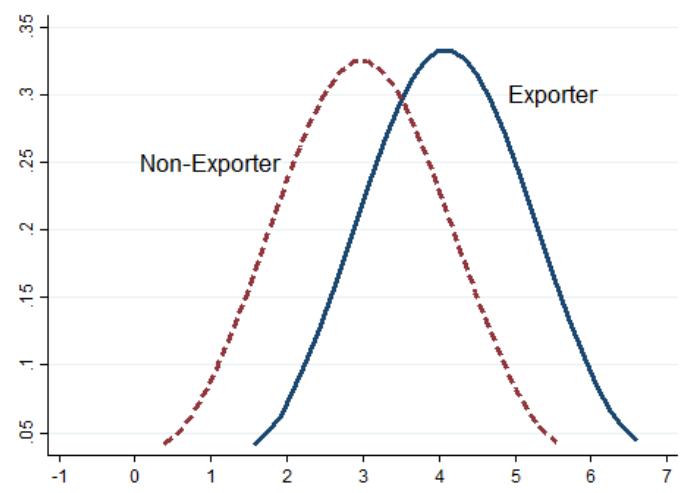

Exporters vs. Non-Exporters
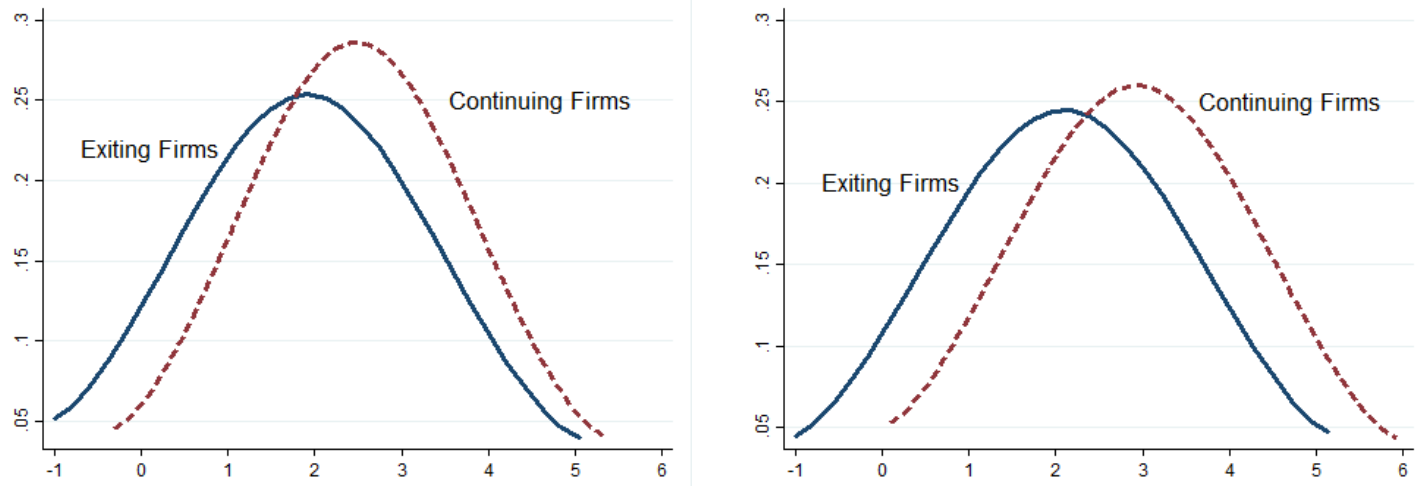

Exiting vs. Continuing Establishments

Note: Top panel shows the distribution of log employment of exporting and non-exporting establishments in Canada in 1996 and the US in 1997. Bottom panel shows distribution of log employment of exiting and continuing establishments in Canada in 1988 and US in 1987. Exiting plants leave the data between 1988 and 1996 (Canada) or between 1987 and 1997 (US). Continuing plants are in the data in the initial and final years. Statistics calculated from the micro-data of manufacturing firms in Canada and the US

Eaton et al. (2011) and Fernandes et al. (2020)), our approach to calibration is distinct in its focus on leveraging domestic micro-data, rather than multi-lateral exporting firm micro-data, to estimate heterogeneity in domestic production and exporting fixed costs.

\subsection{Model Calibration}

Table 4 summarizes the key parameters of the two models. In both models, we assume $\sigma=3.7$ and $\theta=2.9$ and take as given employment in manufacturing in the two countries. 
In the model where all firms have common fixed production and exporting cost (Melitz and Redding (2015)), we then choose the parameters in the first column in Table 4 to fit the trade share, the number and relative employment of exporting and non-exporting firms, and the exit rate in the two countries. ${ }^{16}$ The first column in Table 4 shows the parameters we use for this model. ${ }^{17}$

Table 4: Parameters for Canada

\begin{tabular}{lcc}
\hline & $\begin{array}{c}\text { Melitz-Redding } \\
\text { truncated } \\
\text { Pareto only }\end{array}$ & $\begin{array}{c}\text { Full model } \\
\text { truncated Pareto } \\
\text { fixed cost heterogeneity }\end{array}$ \\
\cline { 2 - 3 } Productivity Pareto truncation & 3.8 & 4.3 \\
Trade friction $\tau$ & 2.15 & 2.15 \\
Entry fixed cost & 0.83 & 0.83 \\
Production fixed cost intercept $f_{d}$ & 0.65 & 0.2 \\
Production fixed cost slope $\beta$ & - & 3 \\
Export fixed cost location $f_{x}$ & 0.6 & 0.09 \\
Export fixed cost shape $\alpha$ & - & 0.17 \\
Exit shock standard deviation & 0.07 & 0.051 \\
\hline
\end{tabular}

Notes: Column 1 shows the model parameters for the model with a truncated Pareto distribution and common fixed costs (the Melitz and Redding (2015) model). Column 2 shows the calibrated parameters for the model a truncated Pareto distribution and heterogeneity in fixed costs of production and exporting. See Table 10 in the appendix (section A4) for US parameters.

Our second model, which features heterogeneity in fixed production and export costs, has two more parameters: the elasticity of production fixed costs with respect to firm productivity $\beta$ and the shape parameter of the Pareto distribution of export fixed cost $\alpha$. We choose these additional parameters using data on the overlap in firm size between exporting and nonexporting firms and exiting vs. continuing firms in Canada and the US. ${ }^{18}$ The second column in Table 4 reports the parameters of the model that allows for overlap in the distribution of

\footnotetext{
${ }^{16}$ Table 9 in the appendix (section A5) shows the values of the moments we target.

${ }^{17}$ Table 4 only shows the model parameters for Canada. Table 10 in the appendix (section A6) shows the parameters for the US.

${ }^{18}$ Specifically, we target the 20th, 50th, and 80th percentiles of the employment distribution of exporting versus non-exporting firms, and continuing versus exiting firms. Table 9 in the appendix (section A5) shows the precise moments of the firm size distribution we target.
} 
exporters and non-exporters and exiters and continuing firms. We need a very high level of dispersion in the fixed exporting costs to match the degree of overlap in employment between exporters and non-exporters in the data, with a (Pareto) shape parameter of $\alpha=0.17$ for Canada. In addition, we need a positive elasticity of fixed operating cost with respect to productivity to match the overlap in the distribution of exiters vs. continuing firms. The appendix (sections A4 through A6) provides more detail on our calibration.

Figure 2 shows what the trade elasticity would have to be in the ACR formula to match the welfare gains from our models for different changes in the iceberg trade cost. As can be seen, the estimated model parameters imply significant departures from an iso-elastic import demand structure, so we know that accurately measuring welfare gains in the model simulated data requires more than the unique constant trade elasticity and change in the trade share used by the ACR formula. Of course, this observation alone does not tell us the degree of bias if we use ACR's statistic or other formulas for data generated by these two models, which is a question we address in section 5.3.

Figure 2: Heterogeneous Trade Elasticities in Simulated Models

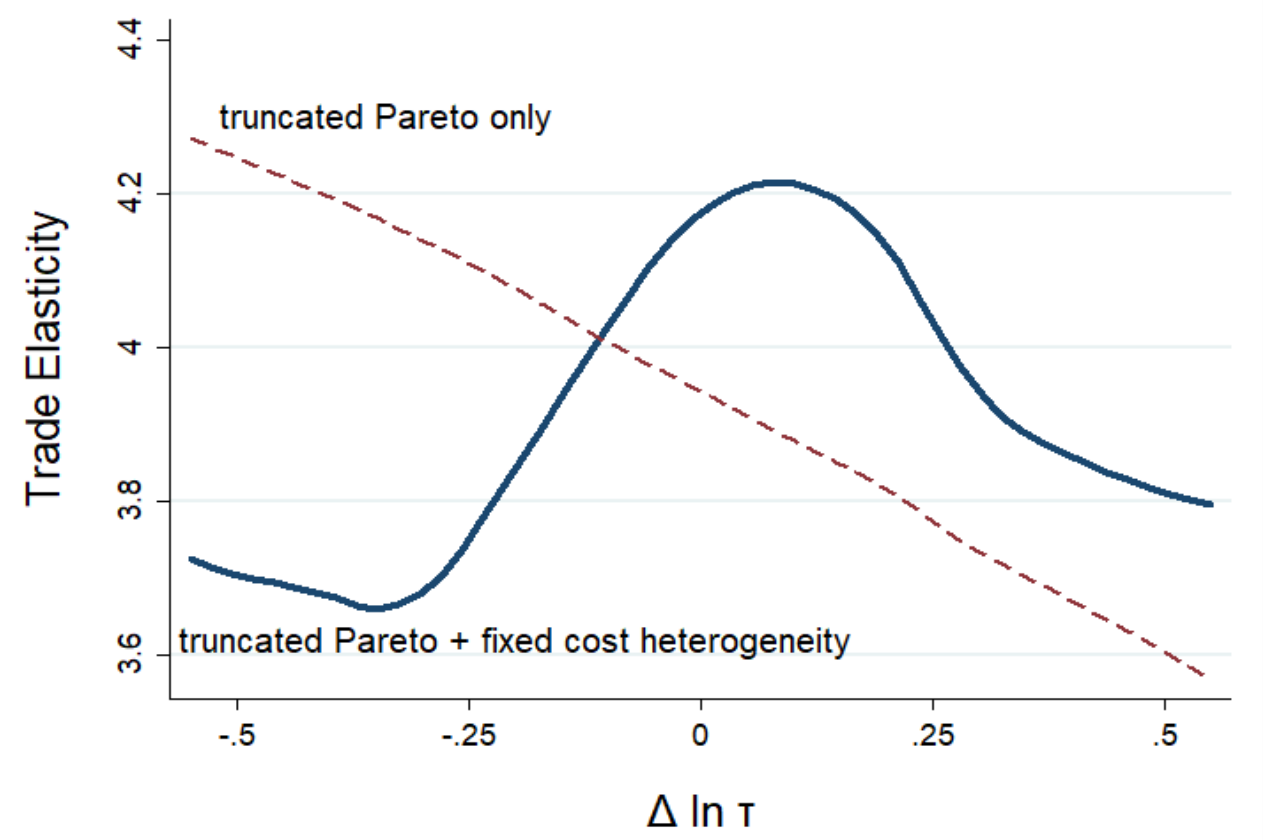

Note: Figure shows the simulated trade elasticity for different values of changes in trade cost in the model with a truncated Pareto distribution only and the model that also has heterogeneity in production and export costs. See text for details. 


\subsection{Predicted welfare effects of CUSFTA}

We now simulate the effect of the reduction in trade costs due to CUSFTA on Canada in the two models. We assume that Canadian trade costs for US imports fell by $23 \%$ due to CUSFTA. This is based on a $16 \%$ decline in the effective tariff rate combined with additional reductions in non-tariff barriers equivalent to $7 \%$ tariff. ${ }^{19}$ On the US side, CUSFTA lowered US tariffs on Canadian imports by about $58 \%$ of the decline in Canadian tariffs on US imports. So we assume that US trade costs for Canadian imports fell by $13.3 \%$ due to CUSFTA. ${ }^{20}$

The first panel in Table 5 shows the predicted change of the key data moments in response to the change in trade costs due to CUSFTA in the two models. For comparison, the table also replicates the same moments in the data in column $1 .{ }^{21}$ Recall that we are using the models to isolate the effect of trade cost reductions so these are not moments that we target in our calibration. In the first row, we show that the growth in the domestic market share of continuing Canadian firms is lower in both models than in the data but that both models capture about two-thirds of this growth. This is because the share of exiting firms is lower in both models than in the data. The second row shows the change in the trade share, i.e. the share of all domestic firms. The model with only a truncated Pareto distribution predicts a change in the domestic spending share almost exactly in line with the data, while the model that also allows for heterogeneity in export and production fixed costs predicts about $80 \%$ of the fall in the domestic spending share. The third row, the share of continuing domestic firms in domestic spending, is simply the sum of the previous two rows and the key summary statistic in equation (1).

The fourth row shows the change in welfare. In the data, this is about $5 \%$. The MelitzRedding model predicts that CUSFTA increased welfare by $5.9 \%$, while the predicted gains

\footnotetext{
${ }^{19}$ See Trefler (2004) for the reduction in tariffs and Head and Ries (2001) for evidence on the tariff equivalent of non-tariff barriers.

${ }^{20}$ In Table 11 in the appendix (section A7) we also consider a simulation where fixed exporting costs fall by a similar magnitude as tariffs, i.e. the fixed cost of exporting to Canada falls by $23 \%$ and the fixed cost of exporting to the US falls by $13 \%$. Unsurprisingly, this results in larger changes in all of the table entries for both models. It has a much larger effect in the Melitz-Redding model than our full model because the dispersion of export fixed costs is so large in our model that there are many fewer marginal firms induced to export due to a proportionate reduction in export fixed costs relative to a truncated Pareto model with common export fixed costs. We focus our analysis on changes in variable trade costs as we are not aware of direct evidence or previous studies that quantify changes in fixed exporting costs during this period.

${ }^{21}$ Specifically, "data" refers to the "difference" columns in Tables 2 and 3.
} 
Table 5: Simulated effects of CUSFTA: Data vs. Model

\begin{tabular}{lccc}
\hline & & $\begin{array}{c}\text { Melitz-Redding } \\
\text { Truncated } \\
\text { Pareto Only }\end{array}$ & $\begin{array}{c}\text { Full model } \\
\text { Truncated Pareto } \\
+ \text { Fixed Cost Het. }\end{array}$ \\
\cline { 2 - 4 } Market Shares: & & & \\
$\Delta \ln X_{j j}^{c} / X_{j j} 1$ & $9.04 \%$ & $6.68 \%$ & $5.91 \%$ \\
$\Delta \ln \lambda^{2}$ & $-22.50 \%$ & $-22.55 \%$ & $-18.04 \%$ \\
$\Delta \ln \lambda^{c} 3$ & $-13.44 \%$ & $-15.87 \%$ & $-12.13 \%$ \\
Total Welfare Change & $4.98 \%$ & $5.88 \%$ & $4.49 \%$ \\
Other moments: & & & \\
$\Delta \ln M_{j j}{ }^{5}$ & $-10.9 \%$ & $-17.39 \%$ & $-14.19 \%$ \\
Exiter relative size ${ }^{6}$ & 0.57 & 0.37 & 0.57 \\
$\Delta \ln M_{i j}{ }^{7}$ & $41.0 \%$ & $53.8 \%$ & $36.05 \%$ \\
$\Delta \ln X_{i j}^{c} / X_{i j}{ }^{2}$ & $4.16 \%$ & $20.11 \%$ & $6.16 \%$ \\
\hline
\end{tabular}

1 Percentage change in domestic revenues of continuing Canadian firms/all Canadian firms. (Difference to 1978-1988 pre-trend.)

${ }^{2}$ Percentage change in total domestic sales of all Canadian firms/total sales in Canadian market. (Difference to $1978-1988$ pre-trend.)

${ }^{3}$ Percentage change in total domestic revenues of continuing Canadian firms/total sales in Canadian market. (Difference to 1978-1988 pre-trend.)

${ }^{4}$ Gains from trade calculated from equation (1) from simulated data. Note: Simulated effect of a $23 \%$ (13\%) reduction in Canadian (US) tariffs in model with a truncated Pareto distribution of productivity and common fixed costs (column 2) and heterogeneous fixed costs (column 3). "Data" in top panel is the difference between the annualized change in 1988-1996 compared to 1978-1988 shown in Table 2, accumulated over 8 years. See text for details. ${ }^{5}$ Percentage change in count of Canadian plants 1988-1996.

${ }^{6}$ Relative size of exiting Canadian plants (1988-1996) relative to all plants in 1988.

7 Percentage change in US exporting plants 1987-1997 from US Manufacturing Census.

${ }^{8}$ Percentage change in total revenues of continuing US exporting firms/total sales of exporting firms from US Manufacturing Census.

in the model that also allows for heterogeneity in fixed costs are closer to the gains suggested by the raw data, at $4.5 \%$. So the full model suggests that CUSFTA "explains" about $90 \%$ of the welfare gains reported in our earlier before-after analysis, while the model that only allows for truncation in the Pareto distribution suggests that CUSFTA accounts for about $120 \%$ of the observed gains.

The last four rows present other data moments from the 1988-1996 CUSFTA period for comparison with those generated by our calibrated models in response to the decline in trade costs. The model with only a truncated Pareto distribution in column 2 generates too much domestic exit, domestic exiters that are too small, there are too many new US exporters, 
and there is too much US export growth coming from the extensive margin. The model with heterogeneous fixed costs fits the data moments much better as it leads to domestic exit by fewer but larger firms, and leads to less import growth on the extensive margin.

\subsection{Comparing welfare statistics}

The last thing we do is compare alternative welfare statistics applied to our two calibrated models. Remember that the estimated parameters for our two models imply that the import demand is not iso-elastic. The question then becomes, how large is the bias if we were to use welfare statistics that assume iso-elasticity? And how large is the bias if we use welfare statistics that allow for deviations from iso-elasticity but still assume strict productivity-based sorting into markets?

The answer depends on what the two models predict in terms of the change in $\lambda$, as well as the elasticity $\theta$. Table 6 shows the gains from trade liberalization that one would estimate using various formulas applied to the simulated data from the two models. The first row presents the true model-implied welfare gains (Table 5), which one could have estimated on simulated data using our formula (equation 1) since both models satisfy our formula's assumptions. The second and third rows use ACR's formula calculated from the simulated data and using the same two estimates of $\theta$ (2.9 and 2.65) we used earlier. In both cases, the gains from trade calculated from ACR's formula are larger than the true welfare gains.

The last two rows in Table 6 show the gains from trade calculated from formulas that do not assume an iso-elastic import demand function. The first formula, from Melitz and Redding (2015) and Head et al. (2014), is a local approximation to the gains from trade that holds for any productivity distribution:

$$
\Delta \ln W_{j}=-\frac{1}{\epsilon_{L}} \Delta \ln \frac{\lambda_{j j}}{M_{j}^{e}}
$$

where $M^{e}$ is the number of potential entrants and $\epsilon_{L}$ is the local trade elasticity. Note that the number of potential entrants $M^{e}$ is not something that can be observed empirically, but we assume that an analyst can observe the true model-implied values of these variables. As for the local trade elasticity, Bas et al. (2017) propose an estimator given by $\epsilon_{L}=(1-\sigma)+$ 
Table 6: Welfare Measurement in Simulated Data

\begin{tabular}{|c|c|c|}
\hline$\underline{\text { Welfare Statistic }}$ & $\begin{array}{c}\text { Melitz-Redding } \\
\text { Truncated } \\
\text { Pareto Only }\end{array}$ & $\begin{array}{c}\text { Full model } \\
\text { Truncated Pareto } \\
+ \text { Fixed Cost Het. }\end{array}$ \\
\hline Model welfare gains (measurable by $-\frac{1}{\sigma-1} \Delta \ln \lambda_{j j}^{c}$ ) & $5.9 \%$ & $4.5 \%$ \\
\hline $\mathrm{ACR}, \theta=2.9^{1}$ & $7.8 \%$ & $6.2 \%$ \\
\hline $\mathrm{ACR}, \theta=2.65^{2}$ & $8.5 \%$ & $6.8 \%$ \\
\hline Melitz and Redding (2015), local elasticity ${ }^{3}$ & $6.2 \%$ & $3.8 \%$ \\
\hline Melitz and Redding (2015), $\Delta$ lowest prod. ${ }^{4}$ & $6.0 \%$ & $0 \%$ \\
\hline
\end{tabular}

1 ACR welfare statistic with extensive-margin based estimate of trade elasticity $\theta=$ $-\Delta \ln \left(\frac{M_{i j} / M_{j j}}{\tilde{\varphi}_{i j} / \tilde{\varphi}_{j j}}\right)$ or using Zipf's Law calculated as $\theta=\xi \cdot(\sigma-1)$ where $\xi$ is the elasticity of firm rank with respect to firm employment.

${ }^{2}$ ACR welfare statistic with arc-elasticity proposed by Melitz and Redding (2015) and defined by $\theta_{\text {arc }}=\Delta \ln \frac{\left(1-\lambda_{j j}\right) / \lambda_{j j}}{\left(1+\tau_{i j}\right)}$

${ }^{3}$ Local welfare statistic (3) with elasticity estimation using $\epsilon_{L}=(1-\sigma)+\frac{1}{X_{j j} / X_{j j}^{M I N}} \cdot \Delta \ln \frac{M_{j j}}{\tau_{i j}}$ from Bas et al. (2017)

${ }^{4}$ Welfare statistic based on change in minimum productivity $\Delta \ln W_{j}=\Delta \ln \varphi_{d}$, where $\varphi_{d}$ is the productivity of the marginal firm.

Note: Simulated effect of a 23\% (13\%) reduction in Canadian (US) tariffs in model with a truncated Pareto distribution of productivity and common fixed costs (column 1) and heterogeneous fixed costs (column 2). See text for details.

$\frac{1}{\bar{X}_{j j} / X_{j j}^{M I N}} \cdot \frac{d \ln M_{j j}}{d \ln \tau_{i j}}$, where $\bar{X}_{j j} / X_{j j}^{M I N}$ denotes the ratio of the sales of the average firm to the smallest firm. In our simulated data, this formula gives us $\epsilon_{L}=3.75$ and $\epsilon_{L}=2.74$ for the models in columns 1 and 2 in Table 6 , respectively.

The local approximation of the gains from trade given by equation (3) is shown in row 4 in Table 6. As can be seen, the gains from trade calculated from the local approximation are very similar (within 5\%) to the true welfare gain shown in the first row. The difference of course is that equation (3) is valid only for small changes in trade costs, while we simulate a fairly large $23 \%(13 \%)$ reduction in trade costs in Canada (the US). However, note that in our full model with fixed cost heterogeneity, the local approximation is strongly downward biased (by about 15\%) relative to true welfare gains.

The last row in Table 6 shows the gains from trade calculated as the change in the minimum productivity of surviving firms. Head et al. (2014) and Melitz and Redding (2015) show that 
the minimum productivity is a sufficient statistic for the gains from trade for any change in trade costs and for any productivity distribution, but this insight is only valid when all firms face the same fixed cost of production and exporting. In contrast to $M^{e}$ which is unobservable in data, the productivity of the smallest surviving firm can potentially be observed and is readily available in our simulated data. Not surprisingly, the gains from trade calculated from this statistic in the Melitz and Redding (2015) model (column 1) is almost identical to the true welfare gain. This is not the case in the full model that also features heterogeneity in fixed costs. In the simulation of that model, shown in column 2 , the productivity of the smallest surviving firm does not change due to CUSFTA so the gains from trade from CUSFTA predicted by that statistic is zero. The reason is of course heterogeneity in fixed costs, where some low productivity firms survive when trade costs fall because these firms face low exporting fixed costs and sell to the much larger US market.

\section{Conclusion}

We propose a new sufficient statistic to measure ex-post welfare gains in trade models for which the import demand system is not necessarily iso-elastic. This includes a Ricardian model of trade with an arbitrary distribution of productivity and a Melitz model with any pattern of selection into exporting and production as well as any distribution of productivity. The statistic is simple to calculate, as it is just a function of one data moment, the market share of continuing domestic firms, and one parameter, the elasticity of substitution across varieties. When applied to the CUSFTA liberalization period, our statistic indicates an approximately $5 \%$ increase in Canadian welfare due to the combination of net domestic exit, net foreign entry and cheaper foreign varieties. These gains are substantially lower than would be implied by statistics that impose iso-elastic import demand on our setting and estimate the elasticity using standard data moments.

There are however some limitations of our proposed statistic. First, it does not measure the potential effect of trade liberalization on productivity growth among incumbent domestic firms (except when applied as described in the appendix (section A2)). Second, the statistic by itself does not tell us what fraction of the implied welfare change is due to changes in 
trade costs. These limitations are common to other approaches that have been proposed in the literature and highlight the challenge of applying statistics derived from models assuming fixed productivity distributions and well-identified trade cost comparative statics to real world data from trade liberalization episodes. We addressed the second limitation by calibrating a generalized Melitz model to data moments that are likely to be important for the extensive margin effects of a simulated trade shock, such as the overlapping size of exporters and nonexporters and the relatively high exit rates of large firms in the pre-CUSFTA period. The simulated gains from CUSFTA trade cost reductions in our model were roughly comparable to the observed gains in the post-CUSFTA period. We find that applying welfare statistics that assume iso-elastic import demand or strict productivity-based sorting into export and exit demonstrate bias in our model simulated data as well.

A third limitation of our statistic is that it can be only be applied to measure ex-post welfare gains, and cannot tell us the gains from counter-factual changes in trade costs such as a hypothetical liberalization scenario or a hypothetical return to autarky. Outside of the fairly restrictive class of modeling assumptions that generate iso-elastic import demand, there are two approaches to this issue. One is to take a stand on a specific model (i.e. specifying the parametric distribution of firm productivity and fixed costs, as in Fernandes et al. (2020)), which we do here by leveraging micro-data moments related to firm size and domestic and foreign market entry/exit. An alternative, proposed by Adao et al. (2020), is to estimate nonparametric functions that capture the contribution of firm heterogeneity to the gains from trade, which requires sufficient data and identification assumptions to allow estimation of the shape of these functions in the parameter space of the counter-factual of interest.

We raise one point for future research. In our calibrated model, we interpret the overlap in size between exporters and non-exporters as due to heterogeneity in fixed exporting costs. Similarly, we model the overlap in size between survivors and exiters as reflecting heterogeneity in fixed production costs. That is obviously a simplification, and perhaps not a good one. Our proposed sufficient statistic does not rely on a specific interpretation of this fact, but we hope that future work will provide richer models for this important stylized fact. 


\section{References}

R. Adao, C. Arkolakis, and S. Ganapati. Not-parametric gravity: Measurin the aggregate implications of firm heterogeneity. Working Paper, 2020.

C. Arkolakis, A. Costinot, and A. Rodriguez-Clare. New trade models, same old gains? American Economic Review, 102(1):94-130, 2012.

R. Armenter and M. Koren. Economies of scale and the size of exporters. Journal of the European Economic Association, 13(3):482-511, 2015.

M. Bas, T. Mayer, and M. Thoenig. From micro to macro: Demand, supply and heterogeneity in the trade elasticity. Journal of International Economics, 108:1-19, 2017.

C. Broda and D. Weinstein. Globalization and the gains from variety. Quarterly Journal of Economics, 121(2):541-585, 2006.

L. Caliendo and F. Parro. Estimates of the trade and welfare effects of nafta. Review of Economic Studies, 82(1):1-4, 2015.

B. Chen and D. Jacks. Trade, variety, and immigration. Economic Letters, 117:243-246, 2012.

J. Di Giovanni and A. Levchenko. Firm entry, trade and welfare in zipf's world. Journal of International Economics, 2013.

J. Dixon and A.-M. Rollin. Firm dynamics: Employment growth rates of small versus large firms in canada. Statistics Canada Research Paper, 11-622-M(25), 2012.

J. Eaton and S. Kortum. Technology, geography and trade. Econometrica, 70(5):1741-1779, 2002.

J. Eaton, S. Kortum, and F. Kramarz. An anatomy of international trade: Evidence from french firms. Econometrica, 79(5):1453-1498, 2011.

R. Feenstra. New product varieties and the measurement of international prices. American Economic Review, 84(1):157-177, 1994. 
A. Fernandes, P. Klenow, S. Meleshchuk, M. Pierola, and A. Rodriguez-Clare. The intensive margin of trade: How big and how important? Working Paper, 2020.

K. Head and J. Ries. Increasing returns versus national product differentiation as an explanation for the pattern of u.s.-canada trade. American Economic Review, 91(4):858-876, 2001.

K. Head, T. Mayer, and M. Thoenig. Welfare and trade without pareto. American Economic Review Papers and Proceedings, 104(5):310-316, 2014.

C. Hottman, S. Redding, and D. Weinstein. Quantifying the sources of firm heterogeneity. Quarterly Journal of Economics, 131(3):1296-1364, 2016.

C.-T. Hsieh, N. Li, R. Ossa, and M.-J. Yang. Accounting for the new gains from trade liberalization. Journal of International Economics, 127, 2020.

I. Kondo, L. Lewis, and A. Stella. On the u.s. firm and establishment size distributions. Federal Reserve Board, working paper, 2019.

P. Krugman. Scale economies, product differentiation and the pattern of trade. American Economic Review, 70(5):950-959, 1980.

L. Kueng, M. Yang, and N. Li. The impact of emerging market competition on innovation and business strategy: Evidence from canada. Journal of Economic Behavior and Organizations, 2020.

M. Kugler and E. Verhoogen. Prices, plant size, and product quality. Review of Economic Studies, 79(1):307-339, 2012.

M. Melitz. The impact of trade on intra-industry reallocations and aggregate industry productivity. Econometrica, 71(6):1695-1725, 2003.

M. Melitz and S. Redding. New trade models, new welfare implications. American Economic Review, 165(3):1105-46, 2015.

M. Melitz and D. Trefler. Gains from trade when firms matter. Journal of Economic Perspectives, 26(2):91-118, 2012. 
E. Oberfield and D. Raval. Micro data and macro technology. Working Paper, Princeton University, 2014.

J. Sutton. Sunk costs and market structure. MIT Press, 1991.

D. Trefler. The long and short of the canada-us free trade agreement. American Economic Review, 94(4):870-895, 2004. 


\section{Appendix}

\section{A1: Arkolakis et al. (2012) and Melitz and Redding (2015) as a special case of equation (1)}

We now show how other sufficient statistics for the welfare gains from trade proposed in the literature can be derived as special cases of our formula (1). Consider first the case of general productivity distributions but strict sorting into production and export, i.e. the Melitz (2003) model where firms face a common fixed cost of production and exporting and sort based on productivity only. With strict sorting, the term $M_{j j} \tilde{p}_{j j}^{1-\sigma}$ is proportional to the mass of firms that pay the fixed entry cost $\left(M^{e}\right)$ and the average productivity of firms above the domestic productivity cutoff $\left(\varphi_{d}\right)$, so $M_{j j} \tilde{p}_{j j}^{1-\sigma} \propto M_{j j} \tilde{\varphi}_{j j}^{1-\sigma}=M^{e} \delta\left(\varphi_{d}\right)$ and $\delta\left(\varphi_{d}\right) \equiv \int_{\varphi_{d}}^{\varphi_{\max }} \varphi^{\sigma-1} d G(\varphi)$. This yields an alternative to our formula for global welfare changes $\left(\Delta \ln M_{e}+\Delta \ln \delta\left(\varphi_{d}\right)\right)$ but one that relies on more restrictive assumptions (strict sorting based on productivity) and is less practical to implement given that neither $M_{e}$ nor $\delta\left(\varphi_{d}\right)$ are easily observed in data. Head et al. (2014) and Melitz and Redding (2015) show how to derive an expression for local welfare changes from this formula. Here we follow Melitz and Redding (2015) who observe that $d \ln \delta\left(\varphi_{d}\right)=-\gamma\left(\varphi_{d}\right) d \ln \phi_{d}=-\gamma\left(\varphi_{d}\right) d \ln W$, where $\gamma\left(\varphi_{d}\right)$ is the hazard function for the distribution of $\log$ firm size within a market evaluated at the domestic productivity cutoff $\varphi_{d}$. The welfare change (1) can then be expressed as

$$
d \ln W_{j}-d \ln \tilde{\varphi}_{j j}^{c}=-\frac{1}{(\sigma-1)+\gamma\left(\varphi_{d}\right)} d \ln \frac{\lambda_{j j}}{M_{j}^{e}}
$$

The term $(\sigma-1)+\gamma\left(\varphi_{d}\right)$ can also be expressed as $\nu+\left[\gamma\left(\varphi_{d}\right)-\gamma\left(\varphi_{x}\right)\right]$, where $\nu$ is the partial trade elasticity estimated in a gravity equation that holds the domestic productivity cutoff constant.

Melitz and Redding (2015)'s analysis raises a number of empirical challenges for using equation (4) to measure local changes in welfare in response to trade shocks, which is why we use this approach only in section 5 but not in section 4 . In particular, they emphasize that in models with strict sorting into production and export, the partial trade elasticity $\nu$ is potentially variable and depends on the shape (hazard function) of the productivity 
distribution at the export productivity cutoff $\left(\nu=\sigma-1+\gamma\left(\varphi_{x}\right)\right)$. Moreover, even with an estimate of the partial trade elasticity, we need information on the shape of the productivity distribution at both the domestic and export productivity cutoffs (the hazard differential $\left.\left[\gamma\left(\varphi_{d}\right)-\gamma\left(\varphi_{x}\right)\right]\right)$ and on changes in the number of (unobserved) firms paying the fixed entry cost in the domestic country $M_{j}^{e}$ to approximate local welfare changes. We also note that although the term $d \ln M_{j}^{e}$ is quantitatively small in Melitz and Redding (2015), for the modest changes in trade costs in our simulated model it significantly affects welfare calculations. Additionally, note that the local formula in equation (4) only allows the quantification of small trade shocks and therefore local welfare changes. To evaluate global welfare changes implied by large trade shocks, the implementation of (4) would require information on the curvature of $\delta\left(\varphi_{d}\right)$ for the equilibria being compared.

These issues make an implementation of Melitz and Redding's approach challenging, which is why empirical researchers may prefer to use the following approach based on Arkolakis et al. (2012). The ACR welfare statistic can be derived as special case of Melitz and Redding (2015). As they observe, under a Pareto productivity distribution, $\gamma\left(\varphi_{d}\right)=\gamma\left(\varphi_{x}\right)=\theta-(\sigma-1)$ where $\theta$ is the Pareto shape parameter. Pareto productivity also ensures that $d \ln M_{j}^{e}=0$. We can then write the global gains from trade as:

$$
\Delta \ln W_{j}-\Delta \ln \tilde{\varphi}_{j j}^{c}=-\frac{1}{\theta} \Delta \ln \lambda_{j j}
$$

where the Pareto shape parameter $\theta$ is also equal to the constant global trade elasticity. ${ }^{22}$ Note that both the Melitz and Redding (2015) and Arkolakis et al. (2012) formulas assume that $\Delta \ln \tilde{\varphi}_{j j}^{c}=0$ but we include these terms above to make explicit that in any empirical application, changes in the productivity of continuing domestic firms and their contribution to welfare are not captured.

Finally, consider the special case where the set of domestic firms is fixed (e.g. the Armington model). The set of domestic firms is fixed $\left(X_{j j}^{c}=X_{j j}\right)$ such that we can substitute the share of continuing domestic firms in total domestic sales $\left(\lambda_{j j}^{c}\right)$ with the trade share $\left(\lambda_{j j}\right)$. The resulting formula for welfare gains then depends only on the intensive margin elasticity

\footnotetext{
${ }^{22}$ Note that Arkolakis et al. (2012) also make the point that their formula applies locally for arbitrary productivity distributions given symmetry and a local estimate of the trade elasticity.
} 
$\sigma$, the change in the trade share, and changes in the productivity of the unchanging set of domestic firms. ${ }^{23}$

The restrictions imposed by strict sorting, Pareto productivity, and no entry/exit all have implications for the domestic net exit term in our more general welfare formula. With Pareto productivity and strict sorting, we would not need to measure that term at all and could replace both $\sigma$ and the domestic exit term with a single Pareto shape parameter $\theta$. With no entry/exit, we would only need $\sigma$ and the trade share to measure welfare. With strict sorting, the productivity of the least productive firm provides a sufficient statistic for welfare or helps to pin down the trade elasticity, as we discuss in Section 5.3. Critically, we use micro data on domestic firm sales to the domestic market during the CUSFTA period to directly measure the domestic net exit term and compare its magnitude to the change in the trade share we observe and the predictions of the more restrictive models.

\section{A2: Restricting the set of continuing domestic firms to capture domestic within-firm productivity effects}

Note that our welfare formula (equation (1)) estimates changes in the real wage up to changes in the productivity of continuing domestic firms. Although these effects are often absent in theoretical models, including the set of models considered by ACR, there is some empirical evidence for within-firm productivity effects of trade liberalization operating through various channels. Most relevant for our setting, Melitz and Trefler (2012) review the literature for CUSFTA and estimate a $5.4 \%$ increase in Canadian manufacturing productivity due to withinfirm productivity growth due to new exporters investing in productivity, existing exporters investing in productivity, and improved access to US intermediate inputs (see their Table 2).

While our analysis is focused on incorporating a flexible extensive margin into analysis of the welfare gains from trade liberalization, our formula can potentially capture welfare gains associated with increases in domestic within-firm productivity, provided one is willing to specify a restricted set of continuing domestic firms that do not have productivity changes.

\footnotetext{
${ }^{23}$ Note that this holds irrespective of whether the foreign country features entry or exit. Balanced trade may require that the terms of trade adjust to reflect changes in exporting status or entry/exit into production for firms in foreign country $i$, which could change the elasticity of the trade share with respect to a change in variable trade costs, but this does not affect welfare gains for domestic country $j$ conditional on the change in the trade share.
} 
By re-calculating equation (1) using the domestic revenue share of domestic continuing firms with no productivity changes, any productivity growth by the other domestic continuing firms is captured by the formula. Intuitively, if we observe a larger fall in $\lambda^{c}$ for the restricted set of continuing firms than the full set of continuing firms, it implies a relative increase in domestic revenues for the non-restricted continuing firms that captures the welfare effects of their increased productivity.

In our setting, a natural way to specify this restriction is to use only domestic continuing firms in sectors that had low initial tariffs in 1988 (and hence minimal tariff reductions due to CUSFTA). Table 7 reports results comparing our welfare estimate using the full set of continuing firms with those that restrict continuing firms to those in sectors with initial tariffs below $5 \%$ or $3 \%$ (recall that $8 \%$ is the nominal average tariff prior to CUSFTA). The results are consistent with increased within-firm productivity in sectors with larger tariff reductions. Using a 5\% threshold, the increase in welfare is only slightly larger, implying only small gains from within-firm productivity growth by domestic continuing firms. With a $3 \%$ threshold, the additional increase in welfare (over our benchmark) is similar in magnitude to the productivity gains estimated in Melitz and Trefler (2012). We stress that these calculations are only meant to be illustrative of the potential for our formula to capture within-firm productivity effects on welfare, as it is challenging to specify which firms are unaffected by a trade liberalization ex-ante and our results based on relative domestic spending shares for different continuing domestic firms are subject to the same caveats about identification as those based on selection effects.

\section{A3: Alternative welfare estimates using import data}


Table 7: Restricting the set of continuing domestic firms to capture domestic within-firm productivity effects

Continuing domestic

firms in:

All sectors (benchmark)

Sectors with initial tariffs below $5 \%$

Sectors with initial tariffs below $3 \%$
Share 1988

$\left(\lambda^{c}\right)$

Share 1996

$\left(\lambda^{c^{\prime}}\right)$

0.503

0.300

0.156

0.345

0.208
Welfare gain 1988-1996

$(\Delta \ln W)$

$5 \%$

$5.2 \%$

$10.7 \%$

Notes: Columns 1 and 2 report the continuing domestic firm share of total domestic spending. Column 3 reports our welfare statistic based on equation (1) (the log difference between column 2 and column 1 divided by $(1 /(\sigma-1))$. Row 1 reports the results calculating the statistics when treating all domestic continuing firms as continuing, while rows 2 and 3 restrict the set of continuing domestic firms to only those in sectors with initial average tariffs (and hence CUSFTA related tariff reductions) below a specific threshold. 
Table 8: Welfare measurement using different measures of imports

\begin{tabular}{lcc}
\hline & $1988-1996$ & Difference \\
\cline { 2 - 3 } Period & CUSFTA (1988-1996) & Difference \\
Source of import data & & \\
\hline \hline & Change in domestic share $\Delta \lambda_{j j}$ \\
Canadian firm exports $^{1}$ & $-23.86 \%$ & $-22.50 \%$ \\
US imports $^{2}$ & $-27.26 \%$ & $-25.18 \%$ \\
World Imports $^{3}$ & $-32.28 \%$ & $-27.79 \%$ \\
& & \\
Canadian firm exports & Welfare change under HLOY formula \\
US imports & $4.38 \%$ & $4.98 \%$ \\
World Imports & $5.64 \%$ & $5.97 \%$ \\
& $7.50 \%$ & $6.94 \%$ \\
Canadian firm exports & & \\
US imports & Welfare change under ACR $(\epsilon=2.9)$ \\
World Imports & $8.23 \%$ & $7.76 \%$ \\
\hline
\end{tabular}

${ }^{1}$ Assumes that total exports by Canadian manufacturing firms measured in ASM is equal to manufacturing imports.

2 Assumes that total manufacturing imports from the US are equal to manufacturing imports (Statistics Canada).

${ }^{3}$ Uses total manufacturing imports from the world (Statistics Canada).

Column 1 reports data for the 1988-1996 period after CUSFTA was signed. Column 2 (Difference) subtracts changes from the pre-period (1978-1988, annualized and converted to an eight year period for comparison) to control for linear trends or "normal" firm entry/exit dynamics from a period without large trade shocks. 


\section{A4: Details on Quantitative Models and Computational Solution Algorithm}

In this appendix we offer a detailed discussion of the quantitative trade models of section 5 that deviate from iso-elastic import demand. Before we begin, it is worth re-emphasizing that our full model exhibits both truncated Pareto firm productivities and overlap in selection. As a result, the model with truncated Pareto firm productivities but strict sorting is a special case of our full model. Since the model with truncated Pareto firm productivities and strict sorting has been extensively analyzed by Melitz and Redding (2015), we mostly focus on our full model, but return to the Melitz and Redding (2015) model in Appendix A5.

To fix ideas, let $\omega$ index different firms in the data, each of which produces a differentiated CES variety. We assume the firms use a production function $y(\omega)=\varphi(\omega) \cdot l(\omega)$, where $y(\omega)$ are physical units of the differentiated variety $\omega, l(\omega)$ is the number of workers firm $\omega$ uses and $\varphi(\omega)$ denotes the firm-specific productivity draw, which we assume is drawn from a Pareto distribution with shape parameter $\theta$ and a truncation parameter. Firm productivity will affect revenues in the domestic market $X_{j j}(\omega)$ as well as export revenues $X_{j i}(\omega)$, where $j$ is the home market and $i$ is the foreign market.

Our first extension of the standard model in Melitz (2003) is that the fixed operating cost firms must pay per period is a deterministic function of the firm's initial productivity draw. That is, for a firm with productivity $\varphi(\omega)$,

$$
f_{j j}(\omega)=f_{d}+\beta \cdot \ln \varphi(\omega)
$$

This assumption is important to account for the fact that large firms might exhibit increased exit in response to a trade shock, so that marginal firms are not exclusively small. Our formulation nests the usual assumption that $\beta=0$, such that all firms face a common fixed operating cost $f_{d}$ as in Melitz (2003). Note that these are still "fixed costs" in the sense that they are invariant to demand shocks, including those related to changes in trade costs. The intuition for this assumption is that high productivity production processes may require higher set-up fixed costs (see Sutton (1991) and Kugler and Verhoogen (2012)). The resulting 
domestic profit net of fixed costs can therefore be defined as

$$
\pi_{j j}(\omega)=X_{j j}(\omega)-w_{j} l_{j j}(\omega)-w_{j} \cdot f_{j j}(\omega)
$$

We model overlap in the size distribution of exporting and non-exporting firms by allowing firms to face different fixed costs of exporting to the foreign market. We follow Armenter and Koren (2015) in modeling these exporting fixed costs as i.i.d. draws, but unlike Armenter and Koren (2015), we build a full general equilibrium two-country model instead of a partial equilibrium model because our statistic stresses the importance of measuring domestic entry and exit. Intuitively we think of the variation in fixed export costs across firms as capturing heterogeneity in exporting opportunities. We assume that these draws follow a Pareto distribution with scale parameter $f_{x}$ and shape parameter $\alpha$ and we will calibrate the shape and the scale parameter to match the overlap in the size of exporters and non-exporters in each country. This leads to the following definition of exports profits:

$$
\pi_{j i}(\omega)=X_{j i}(\omega)-w_{j} l_{j i}(\omega)-w_{j} \cdot f_{j i}(\omega)
$$

Note that if the shape parameter of the Pareto distribution for export fixed costs $\alpha$ is sufficiently high, then export fixed costs are not very dispersed and we return to a world with strict sorting into exports based only on productivity (and hence firm size).

To model selection into exit and exporting, we extend the standard Melitz (2003) framework and directly relate the exit and exporting decisions and therefore connect overlap in exit with overlap in exports. To this end, we allow all firms to finance losses in the domestic markets (inclusive of fixed production costs) with profits in export markets. As a result, the selection equation for exiting can be written as

$$
\pi_{j j}(\omega)+\pi_{j i}(\omega)<0
$$

In other words, a firm will only exit if the sum of domestic and export profits net of fixed costs is negative. Note that in a standard Melitz model with strict sorting, it is unnecessary to allow for the possibility of financing domestic losses with export profits, since a firm will only 
make an export profit if its domestic profits exceed the fixed production costs. In contrast, in our model, export profits can be differently distributed than domestic profits, so that there is the possibility that a firm generates export profits while also generating domestic losses. Additionally, it should be noted that selection equation (9) directly relates overlap along the export margin with overlap along the domestic exit margin.

For the export selection decision, firms must make positive export profits after paying export fixed costs and must have positive profits after paying production and exporting fixed costs.

$$
\begin{aligned}
& \pi_{j i}(\omega) \geq 0 \\
& \pi_{j j}(\omega)+\pi_{j i}(\omega) \geq 0
\end{aligned}
$$

To model entry and exit during the pre-period, we assume that firms face idiosyncratic, proportional productivity shocks drawn from a log-normal distribution with mean 1 and a variance we calibrate to match the pre-period annual exit rate of $9 \%$. The assumption of proportional productivity shocks ensures that firm growth rates are independent of firm size, consistent with Gibrat's law. Firms exit if their profits, net of fixed operating and possibly export fixed costs, become negative as in equation (9). Note that even in the absence of our fixed cost assumptions, random proportional productivity shocks would lead to exit by some firms that are not the smallest in the initial equilibrium. However, the variance of shocks required to match the degree of overlap we observe in the data is extremely high and implies counter-factually high exit rates.

Finally, we follow Melitz and Redding (2015) and model deviations from Pareto productivity by using a truncated Pareto distribution, which adds one additional parameter to the usual two-parameter Pareto distribution. Note that for a given value of the Pareto shape parameter $\theta$, a lower value for the truncation parameter compresses the firm size distribution. This has implications for the relative size of exporters versus non-exporters (used by Melitz and Redding (2015) to calibrate the parameter), the relative size of exiters and continuers, and the overall firm size distribution. ${ }^{24}$

\footnotetext{
${ }^{24}$ Note that setting a low value of the truncation parameter is in some ways equivalent to picking a larger value of the $\theta$ parameter for our simulations, in the sense that both compress the distribution of firm size and generate larger trade elasticities and domestic net exit terms due to the greater importance of marginal firms
} 
Allowing for overlap in exit or export selection implies that exact analytical solutions become infeasible. To understand why, it is important to remember that firm size is by definition not sufficient to perfectly determine whether firms export or exit in any model with overlap. As a consequence, selection cutoffs will be firm-specific and can imply that very productive and large firms might not decide to export due to high export fixed costs, while very unproductive and small firms might export due to low export fixed costs. Additionally, redefining heterogeneity in terms of a summarizing "net profit" term will not collapse firm heterogneity into a single dimension, as domestic and foreign net profits can be distributed differently and respond differently to shocks.

Because these issues make an exact analytical solution impossible, we use a computational solution based on profit-maximization for a discrete number of firms that have productivity and export fixed costs drawn at random. We use a quasi-random Sobol sequence of uniform numbers that, with our chosen parameters, approximate a truncated Pareto distribution for productivity and a Pareto distribution of export fixed costs. Our solution algorithm is as follows:

1. We first guess the number of firms that pay the fixed entry cost in each country and receive productivity and export fixed cost draws. We make an initial guess about which of these firms produce and export to the other market and solve for their equilibrium profits and the terms of trade. ${ }^{25}$

- We determine firm selection, given the current aggregate equilibrium quantities as follows. Given vectors, which track the domestic and export selection decisions, we search for the "most profitable deviations" from the current selection patterns. For example, a firm is currently active in the domestic (or foreign) market might exhibit large profit losses which can be reduced by letting the firm exit the domestic (or foreign) market. Similarly, a firm that is currently not active in the domestic (or foreign) market, might generate much higher profits by participating in the domestic (or foreign) market and therefore enter. We check for the existence of

compared to the (largest) continuing firms. An additional advantage of using a truncated Pareto distribution instead of a Pareto distribution in that our simulation results are more robust to extreme values.

${ }^{25}$ We have experimented with initial guesses that all firms export and produce, or that only the firm with the highest productivity draw exports and produces, obtaining similar results. 
these most profitable deviations from current selection patterns, which can be exit or entry into exporting, production, or both.

- As additional constraints of the most profitable selection moves, we also impose the selection equations (9) and (10). As previously discussed, these conditions allow firms to finance domestic losses (net of production fixed costs) with export profits.

- We continue to check for most profitable deviations until there are no profitable deviations from the equilibrium (within some tolerance to prevent cycling).

2. We then check whether the free entry condition is satisfied, i.e. the total profits in equilibrium are equal to the number of entrants multiplied by the fixed entry cost.

- If not, we increase or decrease the number of entrants, and repeat step 1 to solve for equilibrium given the new set of entrants.

- We repeat step 2 until expected profits from entry, ex-ante, converge to zero (within some tolerance).

While our solution algorithm is much faster than considering every potential combination of firm decisions, simulating a very large number of firms is still computationally costly, so in our simulation each "firm" represents approximately 100 plants in the data.

\section{A5: Details on Calibration of Models and Targeted Moments}

For our calibration, we take $\sigma=3.7$ and $\theta=2.9$ as discussed in section 4 , and normalize the Pareto scale parameter to 1 for both countries. We experimented with an untruncated Pareto distribution for the firm productivity distributions. However, the combination of overlap in selection as well as untruncated Pareto, implies too many very large firms for Canada, which in turn leads to strong deviations from Zipf's Law for firm size. To address this issue, we therefore use the simplest deviation from the traditional Pareto distribution, which is a truncated Pareto distribution as in Melitz and Redding (2015). The combination of a high truncation cutoff for the Pareto distribution of firm productivities and our assumptions on the nature of fixed costs together therefore help us simultaneously match the empirically observed overlap in selection as well as Zipf's Law of firm size. 
Table 9: Data and calibrated moments

\begin{tabular}{|c|c|c|c|c|c|c|c|}
\hline \multirow[b]{2}{*}{ Data moment } & & \multicolumn{3}{|c|}{ Canada } & \multicolumn{3}{|c|}{ US } \\
\hline & & Data & $\begin{array}{c}\text { Full } \\
\text { model }\end{array}$ & $\begin{array}{l}\text { Melitz- } \\
\text { Redding }\end{array}$ & Data & $\begin{array}{c}\text { Full } \\
\text { model }\end{array}$ & $\begin{array}{l}\text { Melitz- } \\
\text { Redding }\end{array}$ \\
\hline $\begin{array}{l}\text { Firm count } \\
\text { (hundreds) }\end{array}$ & & 380 & 430 & 414 & 1610 & 1689 & 1692 \\
\hline $\begin{array}{l}\text { Exporter count } \\
\text { (hundreds) }\end{array}$ & & 137 & 154 & 153 & 290 & 319 & 329 \\
\hline Fraction exporters & & $36 \%$ & $36 \%$ & $37 \%$ & $18 \%$ & $19 \%$ & $19 \%$ \\
\hline Dom. spending share $\lambda_{j j}$ & & $79 \%$ & $79 \%$ & $79 \%$ & $98 \%$ & $99 \%$ & $98 \%$ \\
\hline $\begin{array}{l}\text { Non-exporter size }{ }^{1} \\
\text { (percentile) }\end{array}$ & $\begin{array}{l}20^{t h} \\
50^{t h} \\
80^{t h}\end{array}$ & $\begin{array}{l}0.37 \\
1.00 \\
2.85\end{array}$ & $\begin{array}{l}0.74 \\
1.00 \\
3.40\end{array}$ & $\begin{array}{l}0.85 \\
1.00 \\
1.26\end{array}$ & $\begin{array}{l}0.33 \\
1.00 \\
3.78\end{array}$ & $\begin{array}{l}0.88 \\
1.00 \\
7.46\end{array}$ & $\begin{array}{l}0.79 \\
1.00 \\
1.45\end{array}$ \\
\hline $\begin{array}{l}\text { Exporter size }^{1} \\
\text { (percentile) }\end{array}$ & $\begin{array}{l}20^{t h} \\
50^{t h} \\
80^{t h}\end{array}$ & $\begin{array}{l}0.84 \\
2.25 \\
6.41\end{array}$ & $\begin{array}{l}1.19 \\
2.22 \\
5.07\end{array}$ & $\begin{array}{l}2.51 \\
3.45 \\
6.20\end{array}$ & $\begin{array}{c}2.89 \\
9.23 \\
30.45\end{array}$ & $\begin{array}{c}6.43 \\
10.77 \\
27.34\end{array}$ & $\begin{array}{l}2.76 \\
3.75 \\
6.05\end{array}$ \\
\hline $\begin{array}{l}\text { Exiter size }^{2} \\
\text { (percentile) }\end{array}$ & $\begin{array}{l}20^{t h} \\
50^{t h} \\
80^{t h}\end{array}$ & $\begin{array}{l}0.02 \\
0.31 \\
2.40\end{array}$ & $\begin{array}{l}0.81 \\
0.91 \\
2.13\end{array}$ & $\begin{array}{l}0.60 \\
0.63 \\
0.68\end{array}$ & $\begin{array}{l}0.03 \\
0.37 \\
3.05\end{array}$ & $\begin{array}{l}0.20 \\
0.21 \\
1.04\end{array}$ & $\begin{array}{l}0.60 \\
0.62 \\
0.67\end{array}$ \\
\hline $\begin{array}{l}\text { Continuer size }{ }^{2} \\
\text { (percentile) }\end{array}$ & $\begin{array}{l}20^{t h} \\
50^{t h} \\
80^{t h}\end{array}$ & $\begin{array}{l}0.16 \\
1.00 \\
6.80\end{array}$ & $\begin{array}{l}0.65 \\
1.00 \\
3.55\end{array}$ & $\begin{array}{l}0.71 \\
1.00 \\
2.62\end{array}$ & $\begin{array}{l}0.20 \\
1.00 \\
5.08\end{array}$ & $\begin{array}{l}0.18 \\
1.00 \\
2.26\end{array}$ & $\begin{array}{l}0.71 \\
1.00 \\
2.05\end{array}$ \\
\hline Exit rate & & 0.09 & 0.09 & 0.09 & 0.09 & 0.09 & 0.09 \\
\hline Zipf coefficient ${ }^{3}$ & & $0.56-1.06$ & 1.05 & 1.29 & $0.4-1.06$ & 0.67 & 1.55 \\
\hline
\end{tabular}

1 All exporter vs non-exporter moments are relative to median non-exporter.

2 All exiter vs continuer moments are relative to median continuer.

3 See Dixon and Rollin (2012) Table 8 and Kondo et al. (2019) Table 11.

Sources: Calculated from micro-data of Canada's Annual Survey of Manufacturing or US Manufacturing Census. See text for details

To capture the size differences between Canada and the US, we also take the ratio of manufacturing workers in the US to Canada (similar to the population ratio) as given and equal to 9.1. The standard Melitz model features four additional parameters for each country - the variable trade cost $\tau$, the fixed entry cost $f_{e}$, the fixed operating cost $f_{d}$ and the fixed exporting cost $f_{x}$. We will assume that initial variable trade costs are the same in each 
country.

In the end, our calibration features an additional four parameters for each country the shape parameter for the iid export fixed cost draws $\alpha$, the $\beta$ parameter governing the dependence of fixed operating costs on firm productivity, the Pareto truncation parameter, and the variance of the proportional productivity shocks used to match exit rates during the pre-period.

We pick the model parameters to match several data moments that are standard for calibration of Melitz-style models. We exactly match the domestic spending shares $\lambda_{j j}$ and the fraction of these firms that export and approximately match the number of manufacturing firms in each country (with each simulation firm representing a bit more than 100 establishments). The other standard moment for a model with Pareto productivity is the firm size distribution, which implies a Zipf's law coefficient of $\xi=\frac{\theta}{\sigma-1}$. Note that selection into exporting, even under strict sorting, already leads to some deviation between the Zipf's law coefficient estimated from firm employment and the one implied by a model without exporting. Because of our focus on overlap, we go beyond the single size moment implied by Zipf's law and use multiple novel moments of the firm size distribution to discipline our model. For exporter/non-exporter overlap, we target the 20th, 50th, and 80th percentile plant-level employment for exporters and non-exporters in 1988 for Canada and 1987 for the United States. For continuer/exiter overlap, we target the initial 20th, 50th, and 80th percentile plant-level employment of firms that continue and those that exit over the 1988 to 1996 period (1987 to 1997 period for the United States). ${ }^{26}$ We also target an exit rate of $9 \%$ based on annual exit rates in the pre-period. Our firm size measure is total employment, and we include fixed operating costs and fixed exporting costs (but not fixed entry cost) in the firm employment measures generated by the model. This implies that exporters employ additional labor compared to non-exporters and more productive firms have even higher employment than is predicted by productivity differences alone.

Although we relax the assumptions about strict sorting and allow for deviations from Pareto productivity, we maintain the same assumptions we made in the derivation of equa-

\footnotetext{
${ }^{26}$ Note that for Canada we also have data from the 1978-1988 pre-period, which gives very similar size moments.
} 
tion (1) in section 2. These also help us close the model and solve for the equilibrium. Assuming balanced trade allows us to solve for terms-of-trade/relative wage effects in general equilibrium, and is a reasonable assumption over this period. ${ }^{27}$ Assuming free entry, such that ex-ante expected profits (or total profits net of all fixed costs and the fixed entry costs) are zero, helps solve for the number of firms that pay the fixed entry cost.

\section{A6: Parameters for the US and additional calibration details}

In this section we report the parameters for the US in our two country models and add some details on which moments drive the values of the calibrated parameters for Canada and the US.

Table 10: Parameters and Forcing Variables for US

\begin{tabular}{lcc}
\hline & $\begin{array}{c}\text { Melitz-Redding } \\
\text { Truncated } \\
\text { Pareto only }\end{array}$ & $\begin{array}{c}\text { Full model } \\
\text { Truncated Pareto } \\
\text { fixed cost heterogeneity }\end{array}$ \\
\cline { 2 - 3 } Productivity Pareto truncation & 4.3 & - \\
Trade friction $\tau$ & 2.15 & 2.15 \\
Entry fixed cost & 1.3 & 1.3 \\
Production fixed cost intercept $f_{d}$ & 1.8 & 0.25 \\
Production fixed cost slope $\beta$ & - & 2.72 \\
Export fixed cost location $f_{x}$ & 0.295 & 0.01 \\
Export fixed cost shape $\alpha$ & - & 0.19 \\
Exit shock standard deviation & 0.08 & 0.028 \\
\hline
\end{tabular}

Notes: Column 1 shows the model parameters for the model with a truncated Pareto distribution and common fixed costs (the Melitz and Redding (2015) model). Column 2 shows the calibrated parameters for the model a truncated Pareto distribution and heterogeneity in fixed costs of production and exporting.

As mentioned in section 5, the Pareto truncation parameter influences the size of the largest firms, which is especially important for the US data, as the largest US firms are huge. As a result, the Pareto truncation parameter is either higher than the corresponding parameter for CAN in the Melitz-Redding (truncated-Pareto with strict sorting) model or untruncated

\footnotetext{
${ }^{27}$ Canada-US manufacturing trade was close to balanced over 1988-1996, with Canada running a small bilateral trade surplus that changed only slightly as a share of total trade.
} 
Pareto fits better for our full model with overlap. The Melitz-Redding model does a slightly better job than the full overlap model at matching the size of the largest exporters, but obviously fails to match the overlap in the data. The relatively small amount of truncation we use does not improve the model's ability to fit the relative size of the median exporter to non-exporter in the data, although it provides a better fit to the average size difference as in Melitz and Redding (2015). The Melitz-Redding model implies a Zipf's law coefficient that is significantly higher than any empirical estimate, reflecting the absence of very large firms. By making the largest firms significantly smaller than in the data, the truncated Pareto distribution does increase the size of domestic exiters relative to continuers, even under strict sorting. However the size of exiting domestic firms relative to continuers is still lower than in the data or our full model. Note that choosing a lower truncation point could increase the size of the domestic net exit term and the average size of exiting firms further. This would provide a better fit to the changes we observe during the CUSFTA period, but at the cost of even greater violation of Zipf's law.

Although modeling overlap in the size distribution of continuers and exiters amplifies differences in firm size for a given productivity distribution, it also increases the average revenue of domestic exiters relative to continuers and hence the domestic net exit term when there is a decline in variable trade costs. This occurs because of the heterogeneity in exporting fixed costs implied by overlap. Some smaller firms can offset the decline in domestic profits with profits from exporting, while some larger firms cannot. Combined with the operating fixed cost assumption that makes the most productive firms less profitable, this allows the model to increase the average domestic revenue, and hence importance for welfare, of domestic firm exit.

\section{A7: Simulation of CUSFTA including reductions in fixed exporting costs}

Table 11 presents results similar to those reported in our main Table 5 but also allowing for a reduction in export fixed costs that is proportionate to the reduction in import tariffs. Specifically this means the fixed cost of exporting to Canada falls by $23 \%$ and the fixed cost of exporting to the US falls by $13.3 \%$, similar to the reduction in iceberg trade costs. The additional welfare gains from this change are small, particularly for the full model with fixed 
cost heterogeneity. This reflects the fact that fixed exporting cost heterogeneity is very large in our calibration and the density of firms near the threshold is low, such that average reductions in fixed exporting costs induce only small amounts of entry. In the model with strict sorting, the reduction in average fixed exporting costs leads to somewhat larger effects as marginal exporters are quite large due to the Truncated Pareto productivity distribution.

Table 11: Simulated effects of CUSFTA including reduction in fixed exporting costs

\begin{tabular}{lcc}
\hline & $\begin{array}{c}\text { Melitz-Redding } \\
\text { Truncated } \\
\text { Pareto Only }\end{array}$ & $\begin{array}{c}\text { Full model } \\
\text { Truncated Pareto } \\
+ \text { Fixed Cost Het. }\end{array}$ \\
\cline { 2 - 3 } Market Shares: & & \\
$\Delta \ln X_{j j}^{c} / X_{j j}{ }^{2}$ & $7.50 \%$ & $6.38 \%$ \\
$\Delta \ln \lambda^{2}$ & $-27.05 \%$ & $-19.52 \%$ \\
$\Delta \ln \lambda^{c 3}$ & $-19.55 \%$ & $-13.15 \%$ \\
Total Welfare Change & $7.24 \%$ & $4.87 \%$ \\
\hline
\end{tabular}

${ }^{1}$ Percentage change in domestic revenues of continuing Canadian firms/all Canadian firms.

${ }^{2}$ Percentage change in total domestic sales of all Canadian firms/total sales in Canadian market.

${ }^{3}$ Percentage change in total domestic revenues of continuing Canadian firms/total sales in Canadian market. Note: Simulated effect of a $23 \%$ reduction in Canadian tariffs and fixed cost of exporting to Canada, combined with a $13 \%$ reduction in US tariffs and fixed cost of exporting to US. Table reports models with a truncated Pareto distribution of productivity and common fixed costs (column 1) and heterogeneous fixed costs (column 2). See text for details. 